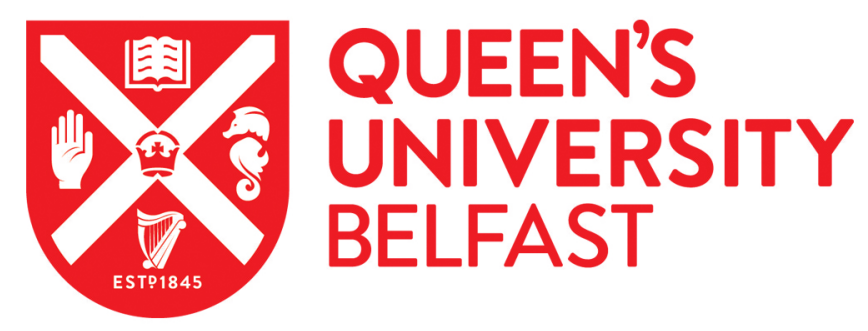

\title{
Academic Students' Progress Indicators and Gender Gaps Based on Survival Analysis and Data Mining Frameworks
}

Marshall, A. H., Zenga, M., \& Kalamatianou, A. (2020). Academic Students' Progress Indicators and Gender Gaps Based on Survival Analysis and Data Mining Frameworks. Social Indicators Research, 151(3), 1097-1128. https://doi.org/10.1007/s11205-020-02416-6

Published in:

Social Indicators Research

Document Version:

Peer reviewed version

Queen's University Belfast - Research Portal:

Link to publication record in Queen's University Belfast Research Portal

Publisher rights

(C) 2020 Springer.

This work is made available online in accordance with the publisher's policies. Please refer to any applicable terms of use of the publisher.

\section{General rights}

Copyright for the publications made accessible via the Queen's University Belfast Research Portal is retained by the author(s) and / or other copyright owners and it is a condition of accessing these publications that users recognise and abide by the legal requirements associated with these rights.

Take down policy

The Research Portal is Queen's institutional repository that provides access to Queen's research output. Every effort has been made to ensure that content in the Research Portal does not infringe any person's rights, or applicable UK laws. If you discover content in the Research Portal that you believe breaches copyright or violates any law, please contact openaccess@qub.ac.uk. 


\title{
Academic students' progress indicators and gender gaps based on survival analysis and data mining frameworks
}

\begin{abstract}
This paper examines gender differences according to two new indicators in higher education studies. One indicator represents the length of studies beyond the minimum requirement and the other represents a harmonised graduation mark. We explore these indicators in a statistical framework that consists of Survival analysis Kaplan Meier methods, Accelerated Failure Time models, Survival Trees, Multivariate Regression Trees and a modified Gender Parity Index. This unique combination of statistical methods allows both to analyse data involving censoring and to incorporate other explanatory variables in the analysis. The approaches were applied to data taken from a Greek and an Italian University and provide evidence that the survival analysis is a useful tool for exploring gender gaps in higher education while the Accelerated Failure Time model permits the investigation of how other variables can influence the gaps. The data mining techniques of survival trees and multivariate regression trees allows for the importance of such influencing variables to be measured and illustrates these in a simple to view tree structure. The Multivariate Regression Tree approach allows us to consider more than one continuous outcome variable so we were able to consider the two proposed indicators simultaneously. Interesting insights from this analysis are that gender has an important role and women outperform regarding these new indicators by taking less length of studies, less graduation time with higher performance, controlling also for other student characteristics. The modified gender parity index enriched the results in all stages.
\end{abstract}

Keywords: Gender Gap, Length of Studies, Performance on Graduation, Survival analysis, Data Mining, Greek and Italian Social Science Students.

\section{Introduction}

Gender is considered to have a fundamental influence on research in higher education. According to Jacobs (1996), the discussion about gender gap "often treats all aspects of education as working to the disadvantage of women". Primarily, inequalities to the detriment of women were sharp and clear regarding the key and essential matter of access to higher education and consequently to degree awards. However, the above reality has changed. Men share of total access to higher education has fallen behind that of women where nowadays women outnumber men in higher education in general in most countries (UNESCO 2009; OECD 2012). Thus, for instance, OECD countries show that on average women accounted for $46 \%$ of enrolments to higher education in $1985,51 \%$ in $1995,53 \%$ in $2000,55 \%$ in 2005 and it is projected to rise to $59 \%$ in 2025 , if past trends continue. This higher propensity of women in higher education seems to motivate a higher attainment of degrees. The trends are the same at least for the OECD member countries (Vincent-Lancrin 2008) where it is 
reported that the gap in degree awards is widening to the benefit of women. On average, 54\% of degrees were awarded to women in 1998, 57\% in 2005 and it is expected to reach $63 \%$ at 2025 .

In the above reality, in Greece and Italy, the two countries which are the centre of this work, interestingly women account for 51\% and 57\% respectively of the enrolments in higher education in 2005 and are expected to show minor changes to $53 \%$ and $57 \%$ in 2025 . Yet, the percentage of women graduates in 2005 is $61 \%$ and 59\% respectively in the two countries while in Italy it is expected to reach $70 \%{ }^{1}$ in 2025 . However, to better understand the situation for Greece and Italy, consider Figure 1(a) which reports the Gender Parity Index $(G P I)^{2}$ for the gross enrolment ratio (women to men enrolled at tertiary level institutions) from 1971 to 2016 for both countries. Obviously, in the early 1970's both countries recorded an inequality in favour of men (GPI is less than 1) but this situation has been reversed in favour of women since 1985 in Greece and 1992 in Italy; the GPI value, (though varies) remains greater than 1, demonstrating that there is no longer an issue for women's access to tertiary education. Figure 1(b) reports the GPI for graduated students from tertiary education in Greece and Italy. The indicator steadily increases for both countries from a situation in favour of men in 1971 ( 0.54 for Greece and 0.76 for Italy) to a state of parity ${ }^{3}$ by the mid 1990's where Greece and Italy are in favour of women.
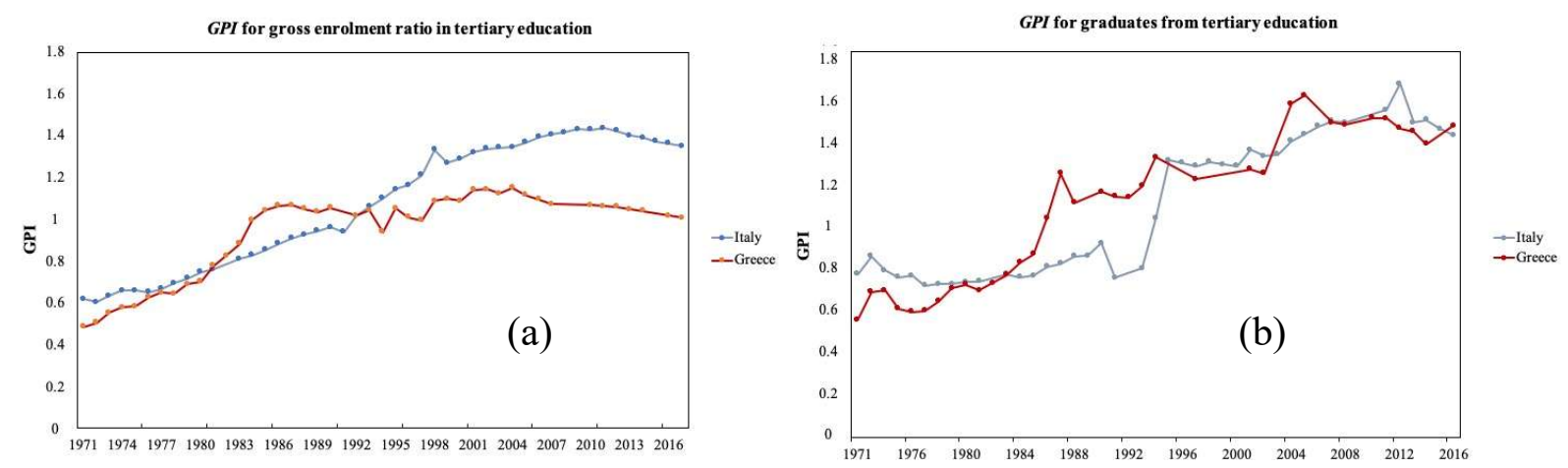

Figure 1: The Gender Parity Index (a) enrolment ratio in tertiary education in Greece and Italy, (b) for graduates from tertiary education in Greece and Italy.

Source: https://data.oecd.org/education.htm, own calculation.

Given the above context where women have outperformed men in terms of enrolment and graduation indicators in higher education, this paper wishes to conduct a more in-depth study to explore the gender gap in an intermediate stage by investigating differences in academic achievements. The detailed analysis will use the more refined variables of the length of studies and the student's final graduation mark, two very strong important indicator in evaluating universities today, according to the literature (Trent and Ruyle 1965; Astin 1972; Berger and Milem 1999; Kalamatianou and McClean 2003; Titus 2006; Buchmann et al. 2008; Aina et al. 2018; Aina 2011;

\footnotetext{
${ }^{1}$ Given the lack of data, the authors could not give the projection at 2025 for Greece.

${ }^{2} G P I$, in general, is the ratio of female to male of the value of an indicator at $t$ time. It will be introduced in detail in Section 3

${ }^{3}$ The parity for Greece was reached between 1985-1986, while for Italy it was reached between 1993-1994 
Woodfield et al. 2006; Trueman and Hartley 1996; Mendick 2005; Gammie et al. 2003; O’Dea et al. 2018; Stinebrickner and Stinebrickner 2012).

In order to conduct the investigation, this paper reports on the analysis of two individual level administrative data sets derived from social sciences-oriented departments of an Italian and a Greek university. A common feature of these data sets, is that there is a minimum time for graduation (threshold for graduation), but there is no maximum for graduation thus provoking the use of censoring to analyse the data, and the statistical methodology described below. The purpose of our paper is therefore twofold:

(1) to investigate differences between male and female students progress through an analysis of length of studies;

(2) to measure gender difference in student performance graduation mark.

To respond to the nature of our data, the statistical approach utilised in the analysis uniquely combines survival analysis with data mining approaches. We also propose that the inequality index used by UNESCO (2017) is modified to represent the differences in gender for academic students' progression. This combination of statistical methods is rather new in applications as ours: some of those methods are used to study the drop out problem (recently Marquez et al. 2016, Perchinunno, Bilancia and Vitale 2019), but not length of studies and graduation mark separately and jointly. Hence, this paper contributes to the discussion by providing evidence through the application of a unique combination of statistical approaches to the student length of studies and graduation mark which are important indicators, used by Universities and policy makers, as mentioned in other parts of this paper.

The paper is structured as follows. In the second Section, we review the literature on gender differences in higher education stating the hypotheses of our research. In Section 3, we describe the statistical framework used for the analysis in this paper, in Section 4 we illustrate the data. Section 5 reports the results and Section 6 presents the study's conclusions.

\section{Literature Review and Hypotheses}

There has been a change in the gender gap in higher education from a position of male dominance to female dominance. During such time of historic reversal, changes were occurring for female students with regard to interuniversity student life and accomplishments like graduation, persistence $^{4}$, attrition ${ }^{5}$ and performance in general. As Jacobs (1996, p. 154) suggests "education is

\footnotetext{
${ }^{4}$ Persistence is the behavior of continuing action despite the presence of obstacles, is an important measure of higher education program effectiveness (Rovai, 2003)
} 
often a relatively advantaged sphere of social life for women", which in return empowers women (Malik and Courtney 2011). Several authors comment on the gender gap reversal in terms of access/enrolment to higher education and graduation. In particular this phenomenon is attributed to changes made in higher education since the second half of the $20^{\text {th }}$ century (Vincent-Lancrin 2008) where there was rapid expansion due to social, economic, and political changes worldwide. In general, the proposed explanations are based on demographic, sociological, economic and educational factors.

From a demographic point of view, the changes in behaviour and policies of legalised contraception help to explain the rise in female participation in higher education in the last century (Goldin and Katz 2002, Bailey 2006). Moreover, the downsizing of families has produced a greater participation in higher education, (Averett and Burton 1996; Ono 2004; Tansel 2002).

The sociological factors consider the reduction in discrimination in the labour market: the abolition of the legal or tacit discrimination and the introduction of the incentives to hire women, gives women increased access to higher education to compete for equal opportunities in employment (Goldin, Katz and Kuziemko 2006; Edwards and Pasquale 2003; Yonezawa and Kim 2008). Another important issue is represented by the decision for women to have a career while having a family: Goldin (2004), basing her theory on observational studies of female cohorts, believes that the possibility of combining a family and a career encourages women to access higher education. In parallel, several other authors (Scott 2006; Ono 2004; Tansel 2002; Alwin Braun and Scott 1992; Dryler 1998; Buchmann and DiPrete 2006; Edwards and Pasquale 2003) report the decline of girls' discrimination within families as an important sociological change to explain the reversed gender gap in higher education.

When considering economic factors, human capital theory suggests that individuals make their decisions to study (or not) in terms of the economic return expected from their studies. From this point of view, higher incentives for one gender could lead to higher rates of participation in higher education. If we consider the wages, the literature does not provide a convincing explanation for the growth inequality in favour of female students. In fact, the increase in the wage premium related to higher education is not significantly higher for women (Dougherty 2005; Jacob 2002; Murphy and Welch 1992; Edwards and Pasquale 2003), moreover women respond less strongly than men to the wage premium on their degrees (Averett and Burton 1996). DiPrete and Buchmann (2006), on the contrary, show that in the United States the return on degrees has increased more strongly for women than men over the past few decades and therefore explaining the difference in the growth in participation in higher education.

\footnotetext{
5 Student attrition is defined as the cessation of individual student membership in an institution of higher education (Bean, 1980) 
The educational factors show that the improvement in the female academic access and progress depends on the increasing improvement of the preparation received in secondary school. The Programme of International Student Assessment (PISA) in 2018 shows that, compared to boys, girls aged 15 years old score much higher in reading ( +30 points on average in tests, decreasing of 9 points from 2006), obtaining comparable results in science ( -2 points on average, remaining constant respect to 2006) and lower in mathematics ( -5 points on average, increasing 4 points from 2006) in respect to the boys. This consideration and the attitude of female students to work harder and more consistently for academic performance and to better manage time (Sommers 2001; Evers and Mancuso 2006; Jorgensen et al. 2009; Woodfield et al. 2006; Trueman and Hartley 1996; Grebennikov and Skaines 2009) helps to explain women's academic success in grade average and beliefs about ability. There is some evidence to suggest that the reversal tendency does not always hold across all fields of study (Wolffensberger 1993; Ayalon 2003; Sax et. al. 2015) or when poverty and other socioeconomic factors are considered (Morley and Lugg 2009).

In this work, we analyse the completion/graduation in higher education involving gender. In general, the access/enrolment in higher education opens the way for enjoying a public good, but it may not be enough if graduation is not ultimately reached. "In order to fully enjoy the benefits of higher education and to contribute to the society and economy in which they live, individuals need to complete their program of study. True progress depends on high levels of completion for all population groups", UNESCO (2009). Hence, the need for research on students' outcomes. This research shows that gender has its own relevance in terms of students' and institutions' success and performance or students' and institutions' efficacy, effectiveness and efficiency. Even though there is no consensus regarding the definition and measurement, those commonly used fit into two categories; degree completion (percentage of degrees completed, non-completed, or rates of completion, drop-out rates) and time-to-degree, more generally length of studies (Tinto 1975, 1993; Spady 1975; Bean 1980, 1983; Bean and Metzner 1985; Astin 1977, 1985; Bayer 1968; Yorke 1999; Braxton et. al. 2000; Johnes and Taylor 1989; Ball and Halwachi 1987; Ishitani 2006; Buchmann and DiPrete 2006; Webster and Showers 2011; Gaither, et al. 1994; Ball and Wilkinson 1994; Draper and Gittoes 2004; Titus 2006; Gentry 2014).

\subsection{Degree Completion}

Until recently, students who left University without successfully completing their degree studies were quite often referred to as dropping out from their University education. In some cases, the term is still being used today but more frequently the preference is to refer to this as student attrition, defined here as the amount of students who unsuccessfully complete their degree, also calculated as 
a rate, or as a percentage of those who enrol at University. Another widely accepted term to attrition is retention; both terms are used interchangeably and just for clarity, completion rates are seen as the opposite of attrition rates where this is the percentage of those that do successfully complete their degree, also referred to as graduation rates. According to the literature, the term student attrition, seems to mostly exist in the US since the early 20th century.

In early studies like McNeely's (1937), higher rates of student mortality are recorded among women. Similarly, Astin, (1964), Panos and Astin (1968), Tinto (1975), Somers (1995), found that women withdraw significantly more than men while on the contrary, other researchers, like Demos (1968), Nelson (1966), Buchmann and DiPrete (2006), mention the inverse trend in specifically men dropping out significantly more frequently. However, in many studies no significant difference was found in overall attrition or dropout rates among men and women students. See for example Summerskill and Darling (1955), Bragg (1956), Slocum (1956), Suddarth (1957), Iffert (1958), Sewell and Shah (1967), Johansson and Rossmann (1973), Astin (1975), Fetters (1977), Embry (1982), Hilton and Schrader (1987), Herzog (2005). Several explanations have been given for the discrepancy in these results. Iffert (1958) found higher retention for women than for men in teachers in colleges and technological institutions. Darley (1962), as cited in Pantages and Creedon (1978), found that gender is an important factor in attrition at some institutions but not at others (e.g., college or university). Astin (1964) and Cope et al. (1971) support this by reporting that women are more likely to drop out when they are attending institutions with a high ratio of men to women. Severiens and ten Dam (2012) find that female students outnumber male students in general, and where one gender group is a minority in the study programme, dropout or course switching is more frequent among the minority students. Panos and Astin (1968) show that women are more likely to drop out than men with comparable high school grade average while Schapiro and O'Malley (1991) found that gender differences were significant regarding 1982 data, but substantially less important in 1984 data and insignificant in 1989 data.

It also seems that these issues emerged concurrently or at least shortly after the demand for higher education exceeded supply and many popular institutions began to set more stringent criteria for introducing students (Berger and Lyon 2005). In the words of Pantages and Creedon (1978), "The need to understand this phenomenon [student attrition] becomes more urgent every day". This interest is mostly due to funding and to human resource planning for higher education graduates at a nationwide or regional level. Educational planners and policy makers require reliable estimates for the completion rates and duration of studies in any particular period to predict future recruitment to industry or to the labour market in general. Even with the focus in the literature on the issue of attrition studies in higher education, few authors have analysed the time-to-graduation in higher education. 


\subsection{Length of Studies}

The definition of length of studies is usually the difference between the initial enrolment in a college to the time a degree is awarded. However, when graduation is not enforced to take place in a prescribed time, the length of studies is a more general term that can be used to capture this previous case and also cases of delayed graduation. In this context, progress to graduation is viewed in an open system, where the student's life is a function of interacting external, intra-institutional and students' characteristics (Berger and Milem 1999; Titus 2006). Moreover, considering the human capital investment model (firstly proposed by Becker in 1962), the time to graduation (in particular the delayed time to graduation) is the results of a sequential process made under gradually decreasing levels of uncertainty on education costs and future returns (Aina et al. 2018). Trent and Ruyle (1965), Astin (1972), Kalamatianou and McClean (2003) found that women are more likely to have a "when it is due" graduation (usually in a four-year sequence) while men are more likely to have a late graduation (beyond a corresponding prescribed time) or even a perpetual studentship (Kalamatianou and McClean 2003). Similar results are mentioned in Buchmann, et al. (2008), Aina et al. (2011) and Löfgren and Ohlsson (1999) who report a lower tendency of men to graduate on time. Similarly, Eckland and Henderson (1981) found that overall Caucasian and black females are more likely than their male counterparts (from the high school class of 1972) to have graduated from college on schedule. For the four-year institutions, women are more likely to graduate on time but more men will eventually graduate as it is suggested that men are more likely to insist on or reenter the education process than women. However, Häkkinen and Uusitalon (2003) and Lassibile and Navarro Gómez, (2011), found a lower tendency of women to graduate on time when they analyse cohorts of students enrolled in short university degrees. Crippa et al. (2016) prove that the gender gap in length of study is a consequence of meeting syllabus requirements for credit attainment.

Finally, it is worth noting that the time to degree and graduation rates have a particular value in gauging the trends towards globalization of both job markets and curricula. Overall it seems that now, graduates do not enjoy a well-loved profession that would encourage them to do better and provide excellent output (Scurry and Blenkinsopp 2011). Graduates' employment status is less certain than in the past where the capability of the labour market in many countries to absorb great numbers of graduates has been highly questioned (Brint 2001; Brown and Hesketh 2004; Scurry and Blenkinsopp 2011). Not surprisingly graduates find themselves in jobs unrelated to their studies. As a result, the motivation of earnings and consequently the social and private returns to those with a degree is therefore not as rewarding as in the past. The changing landscape of graduate jobs means that there is more uncertainty for students as to what career they will have and as such could stall their progress while they deliberate over this, or demotivate them in their course or cause 
them to move course completely. The reverse may also be the case where due to fast, changing career paths, students change career quickly possibly deciding to drop out of the course if they think it is no longer appropriate. Such issues are of recent interest and concern given the high levels of investment made by individuals, organizations and societies in graduates (McGuinness and Byrne 2014; Scurry and Blenkinsopp 2011).

Educational planners and policy makers require reliable estimates for the distribution of duration of studies and completion rates in any particular period to predict future recruitment to industry or to the labour market in general. These estimates relate to institutional operations and funding; the longer the duration of studies the more funding is required (Kalamatianou and McClean 2003; Conger and Dickson 2017). Internal university management and the organization regarding academic and administrative staff, rooms for lectures and examinations, are based on such assessments, while, and most importantly, graduation rates are crucial performance indicators for university departments.

\subsection{Graduation Mark}

Graduation marks present a more informative measure than graduation rates as it reflects a more refined measurement of the performance of the student rather than report on whether they have been successful in graduating or not. There is less research available regarding-gender gap on this issue. McNabb et al. (2002) and Aina (2011) find that, although women students perform better on average than their male counterparts, they are significantly less likely to obtain the higher grades, with no explanation as to why. O'dea et al. (2018) also have strong evidence for lower variation in grades among girls than boys and of higher average grades for girls in STEM faculties. Aina et al. (2011) discover that male students complete their studies in less time, performing a lower final grade than females.

Several authors (Woodfield et al. 2006; Trueman and Hartlley 1996; Mendick 2005; Gammie et al. 2003; O'Dea et al. 2018; Stinebrickner and Stinebrickner 2012) suggest a number of reasons for differences in gender with respect to academic performance. These include: the types of subject being studied, family background, age, marital status or differences in the type and quality of the institutions students attend (Hoskin al. 1997; Rudd 1984). Moreover, gender differences in attainment could be due to psychological and biological factors (Mellanby et al. 2000) or the way in which the students are assessed (Bradley 1993). 


\subsection{Hypotheses}

The focus of this current research aims to measure the gender gap in higher education with respect to student length of studies and final grade at graduation (academic performance). We do so by examining the following hypotheses using data from the social departments in Universities in Greece and Italy:

I. Female students tend to graduate earlier or have a lower length of studies than male students (Trent and Ruyle 1965; Astin 1972; Kalamatianou and McClean 2003; Buchmann et al. 2008; Aina 2011; Löfgren and Ohlsson 1999).

This also holds, controlling for age at enrolment, nationality department and country.

II. Female students perform better and present same variation in the final grade of graduation (McNabb et al. 2002; Aina, 2011).

This also holds, controlling for department.

III. Male students who complete their studies in a comparable time to females obtain a lower final grade than female counterparts (Aina 2011).

This also holds, controlling for age at enrolment, nationality, department and country.

\section{Statistical framework}

To confirm the hypotheses set out above some statistical methods have been used and applied to the available data. These methods include: survival analysis and in particular Kaplan-Meier estimators for capturing the probability of a student to have a length of studies greater than time $t$ (or not get a degree up to time $t$ ), accelerated failure time (AFT) models for capturing the effect of other variables on the length of studies and performance at the University, and regression trees (survival trees and multivariate regression trees) to highlight student characteristics that jointly influence length of studies and performance. Throughout the analysis, we use the internationally recognised Gender Parity Index (GPI) used by UNESCO (2017) and modify this measure to account for the two proposed higher education indicators.

\subsection{Survival analysis}

In the context of survival analysis, $T$ usually represents lifetime or survival time, of an individual up to the occurrence of an event. In our case $T$ represents the length of studies of a student defined as the time duration between the date of first enrolment to a university institution and the date of graduation or the expiry date of the follow-up period. An important feature of survival analysis is 
the method's ability to handle observations defined as right censored data. Right censoring occurs when the units have not experienced the event by the end of a predefined follow up period. In the case of the university students' progression, right censored data represents students that at the end of the follow up period, have not got a degree and are still enrolled at the University. $T$ is a nonnegative random variable assumed to be continuous or discrete. In a survival analysis procedure, a time $T$ is studied through functions that include the density function commonly denoted as $f(t)$ and the distribution function, $F(t)$ given by:

$$
F(t)=P(T \leq t)=\int_{0}^{t} f(u) d u
$$

The density function describes the probability of the occurrence of an event at any given instant $t$ not conditioned on any covariates, hence it is referred to as an unconditional failure rate. $F(t)$ expresses the probability that the lifetime of an individual is less than or equal to some value $t$. The study presented in this paper considers cohorts of students entering University who are observed for a prescribed follow up period (defined in Section 4.1) until the event of possible graduation. Then, a student's probability of getting a degree in fewer than $t$ months is given by $F(t)$.

However, two other functions of $T$, the survival function $S(t)$, and the hazard function $h(t)$ play a central role in survival analysis and, mutatis mutandis, in our application. The survival function defined as:

$$
S(t)=P(T>t)=1-F(t)
$$

expresses the probability that a lifetime $T$ is greater than some time $t$. In practical terms it gives the proportion of subjects surviving beyond $t$. The survivor function, also known as the cumulative survival rate, is strictly decreasing over time as the subjects that have still to experience the event will do so over time. In our work, we consider the survival function as an indicator of academic student's progression representing the probability of a student to have a length of studies greater than $t$ or, in other words, the proportion of students who have not got a degree in a time interval greater than $t$. The assumption is that the longer the length of studies the worse the student's progress. A non-parametric estimator of the survival function $S(t)$, is the Kaplan-Meier estimator (Kaplan and Meier, 1958) or product-limit estimator for the cumulative proportion surviving units at time $t$, given as follows:

$$
\widehat{S(t)}=\prod_{i=1}^{t_{i} \leq t}\left(1-\frac{d_{i}}{n_{i}}\right)
$$

where $t_{i}$ is the observed time when at least one event happened, $d_{i}$ is the number of the events that happened at time $t_{i}$ and $n_{i}$ is the number of units survived at time $t_{i-1}$. The Log-rank test (Mantel and Haenszel 1959) is applied to determine whether there are statistically significant differences in survival functions among groups. The hazard function defined by:

$$
h(t)=\lim _{\Delta t \rightarrow 0} \frac{P(t \leq T<t+\Delta t \mid T \geq t)}{\Delta t}=\frac{f(t)}{S(t)}
$$


represents the rate at which subjects are experiencing the event at $t$, given that they have not experienced the event until $t$. It is a conditional rate also known as the failure rate, the age-specific failure rate, the instantaneous failure rate, the force of mortality and the conditional mortality rate. It also represents the instantaneous "risk" that the individual experiences the even in the time interval $[t+\Delta t]$, given that it has not occurred at or beyond time $t$. Parametric accelerated failure time (AFT) models represent the risk of having the event at time $t$ for statistical modelling of survival data (Wei, 1992) and is estimated as follow:

$$
h(t \mid \boldsymbol{X})=\exp (-\boldsymbol{\beta} \boldsymbol{X}) h_{0}[t \cdot \exp (-\boldsymbol{\beta} \boldsymbol{X})]
$$

where $\boldsymbol{X}=\left(x_{1}, x_{2}, \ldots, x_{p}\right)$ is a vector of $p$ covariates, $\boldsymbol{\beta}=\left(\beta_{1}, \beta_{2}, \ldots, \beta_{p}\right)$ is a vector of coefficients measuring the impact of covariates on the hazard function and $h_{0}(\quad)$ is the baseline hazard. The survival times are usually assumed to follow a parametric distribution that must be specified (e.g., the exponential, Weibull, log-normal or log-logistic) (Hosmer et al. 2008).

\subsection{Regression Tree, Survival Tree and Multivariate Regression Tree}

The CART (Classification and Regression Tree) methodology is a non-parametric tree-structured recursive partitioning method introduced by Breiman et al. (1984). In general, it is an alternative approach to nonlinear regression, a method which belongs to binary decision tree approaches which are built by splitting a node into two child nodes repeatedly, beginning with the root node that contains the whole sample. The use of CART analysis in this paper facilitates the use of covariates in our analysis where we can explore the influence of many variables on the students' outcome variables (length of the studies and the graduation mark).

In regression tree terms, let $T$ represent the dependent variable and $\boldsymbol{X}=\left(X_{1}, X_{2}, \ldots, X_{p}\right)$ be a vector of $p$ covariates. To build the regression tree, the method involves two main stages: growing and pruning. In growing, the $T$ is recursively partitioned into subsets. Each partition is obtained by examining every possible binary split along the observed data $T$ for each predictor variable $X_{1}, X_{2}, \ldots, X_{p}$ and selecting that which most reduces the variability of the node regarding the predicted variable. The variability of the $k$-th node is given by the sum of squared errors:

$$
S S E_{k}=\sum_{i}^{n_{k}}\left(t_{i}-\overline{t_{k}}\right)^{2}
$$

where $n_{k}$ is the number of units belonging to the $k$-th and $y_{k}$ is the average mean of the variable $T$ on the $k$-th. The result is a sequence of nested trees, with increasing numbers of leaves (terminal nodes), until no more splits are possible and the fully-grown tree is reached. The pruning stage of 
the fully-grown tree aims then to select the best subtree and consists of declaring an internal node as terminal and deleting all its descendants.

Survival trees are an extension of the CART methods for censored data. In this case, the log-rank statistic provides a criterion for the goodness of split for each subsequent node. When a training sample, containing time, status and predictor values are fed into the algorithm, the output is a collection of end-nodes which can be described by the parent-branches in terms of predictor values. Each end-node contains the number of total and censored observations falling into a corresponding final category, as well as a Kaplan-Maier estimation of the cumulative survival function of the group units. The results therefore are subgroups of the original survival data split by the characteristics of the individuals in the data set. The literature currently reports the application of the survival trees primarily to medical data. Previous research in this area has been conducted on modelling the length of stay of patients in hospital by Harper et al. (2012). For our research, survival trees will be used to explore the influence of many variables on the student length of studies time.

The multivariate regression tree (MRT) (De'ath 2002) is natural extension of univariate regression trees, where the univariate response of the latter being replaced by a multivariate response. Let $\boldsymbol{Y}=\left(Y_{1}, Y_{2}, \ldots, Y_{r}\right)$ represent the matrix of dimension $(n, p)$ for the $r$ dependent variables and $\boldsymbol{X}=\left(X_{1}, X_{2}, \ldots, X_{p}\right)$ is the matrix of $p$ covariates. As in the univariate case, in MRT exist the growing and pruning stage. The variability of the $k$-th node is based on the sum of squares about the multivariate mean:

$$
S S M_{k}=\sum_{i=1}^{n_{k}} \sum_{j=1}^{r}\left(y_{i j}-\bar{y}_{J}\right)^{2}
$$

where the $y_{i j}$ is the value of the $j$-th dependent variable for the $i$-th unit and $\overline{y_{j}}$ is the mean of the $j$ th dependent variable. In the context of the proposed research in this paper, it will allow for the relationship between many covariates to be explored for both graduation mark and student length of studies to be modelled at the same time.

\subsection{The Gender Parity Index}

The Gender Parity Index (GPI) is a socioeconomic index designed to measure the relative access to education for males and females. This index is commonly used by international organizations, such as UNESCO, but it is poorly mentioned by the literature accounting for gender differences (Hippe and Perrin 2017). The GPI at time $t$ is defined as follows: 


$$
G P I_{t}=\frac{\operatorname{Ind} d_{F, t}}{\operatorname{Ind} d_{M, t}}
$$

where $\operatorname{Ind}_{F, t}$ is the female value of an indicator at $t$ time, while $\operatorname{Ind}_{M, t}$ is the male value of the same indicator at $t$ time. A GPI value equal to 1 indicates parity between females and males. In general, a value less than 1 for (6) indicates a disparity in favour of males and a value greater than 1 indicates a disparity in favour of females. The interpretation should be the other way round for indicators where normally, the approach to $0 \%$ is the ideal (e.g. repetition, dropout, illiteracy rates, etc). In these cases, a GPI of less than 1 indicates a disparity in favour of females and a value greater than 1 indicates a disparity in favour of males. Throughout the analysis in this paper, we will use the GPI as a recognised measure of gender inequality and define the GPI for the performance indicators for the student outcomes under investigation: the length of studies and graduation mark.

\section{Data}

\subsection{Description of the Greek and Italian undergraduate University system}

This subsection presents a brief description of the graduation process for undergraduate courses in Greek and Italian Universities. For both undergraduate systems, students who first enrol in a department/faculty can only graduate if two conditions are satisfied; a) there exists a certain number of course units that must be successfully completed by the students for them to get a degree, b) there is a minimum duration time, which we call threshold of graduation, in which these units can be completed. Graduation is not possible before this minimum time.

The majority of university undergraduate curricula in Greece take the form of four academic years; exceptions correspond to medicine engineering, veterinary science and agriculture. Graduation is possible when the above mentioned two conditions are satisfied, while the required number of course units and its distribution over the academic years is decided by the relevant departments. Examinations take place three times a year usually in June, October and February. Assuming that all enrolments take place on the first day of September of each academic year, graduation is possible just after the June examination period which corresponds to the fourth June that follows the September of the first enrolment. It is assumed that all student graduations take place on the last day of June. This gives a minimum duration of studies equal to 46 months - the threshold of graduation. Students who satisfy the course unit condition can graduate at exactly 46 months after the date of their first enrolment. Students who fail to do so can proceed to the following examination period for an unlimited number of times until the course unit condition is satisfied and they graduate. A full description of the Greek system is given in Kalamatianou and McClean (2003). 
The situation of the Italian University is very similar, the difference is given by the threshold for graduation which is 34 months $^{6}$. Moreover, the opportunity to take examinations for the graduation are more than three or four times a year usually and the dates are decided by the universities and the departments. A full description of the Italian system is given in Crippa et al. (2016).

\subsection{Description of the variables used in the analysis}

Student data are provided by Panteion University in Greece and University of Milano-Bicocca in Italy $^{7}$. The focus is on four cohorts of students who enrolled at the university for the first time from September 2000 to September 2003. Students who transferred to other universities or who dropped out are excluded. Each student was observed from the time of their first enrolment in the university and up to 48 months after the corresponding threshold of graduation. Note that the choice of 48 months, which we call the observation period after the threshold of graduation, gives enough time for students to graduate as also mentioned by Tinto (2012) and Kalamatianou and McClean (2003). For each case (student) the dates of first enrolment and graduation (where there is any) are recorded. Other student features included in the analysis were chosen based on theoretical considerations, previous research on student graduation and their availability in the original dataset. Individual background variables that are treated in the analysis as explanatory include Cohort year, Gender, Age, Nationality, Country, and Department and are fully described in Table 1.

For the purpose of our work, we introduce two new variables, treated in the analysis as dependent variables: Length of studies (LS) defined as the time elapsed (in months) between the date of first enrolment at the university and the graduation date, if any, or the expiration date of the observation period. In order to adequately compare the Greek and Italian systems, we also define the variable Time to Graduation after Threshold (TGaT) as

$$
T G a T=L S-\xi
$$

where $\xi$ is the threshold for graduation, that is equal to 46 and 34 months for the Greek and the Italian students respectively. It is emphasized that the variable TGaT measures the length of studies after the threshold of graduation until the point of actual graduation or to the end of the observation period. The variable being investigated in the survival analysis, is the $T G a T$, the first of our dependent variables. The Event variable (Table 1) is an indicator variable for censorship, taking the

\footnotetext{
${ }^{6}$ We refer to Italian Bachelor's degree, with a minimum legal duration of studies of 3 years (in general, for Italian system, graduation is possible just after the June examination period which corresponds to the third July that follows the September of the first enrolment). From 1998/99 the Italian university system underwent a strong reform considering the principles of the Sorbonne Declaration (25 May 1998) and Bologna Declaration (19 June 1999) which promote the creation of a European Higher Education Area through the harmonization of the different European educational systems. Before this reform threshold time to graduation was 46 months.

${ }^{7}$ The authors declare that data were treated with respect to UE guidelines on privacy. 
values of 1 if graduation takes place during the observation period (of 48 months) and 0 otherwise. It holds that threshold $\leq T G a T \leq 48$.

The Mark variable (Table 1) is the student raw mark at graduation (when present). Because this variable is measured on different scales in the two countries (the Greek scale is $[5,10]$ and the Italian one $\left[66,110\right.$ cum laude $\left.^{8}\right]$ ) its values were harmonized as follows:

$$
G M=\frac{x-\mathrm{m}(x)}{\max (x)-\min (x)}
$$

where $x$ is the initial value of the graduation mark while $\min (x)$ and $\max (x)$ are correspondingly the minimum and maximum values of the scales of the two countries. The harmonized mark $(G M)$ ranges from 0 to 1 and is the second of our dependent variables.

The remainder of the variables, detailed in Table 1 are treated as independent variables and are included in the analysis using dummy variables where the reference category is also mentioned in parentheses in Table 1.

\begin{tabular}{lll}
\hline Name & Description & Code \\
\hline Enrolment* & Date to enrolment & Date: $\mathrm{dd} / \mathrm{mm} / \mathrm{yy}$ \\
Graduation* & Date to graduation & Date: dd $/ \mathrm{mm} / \mathrm{yy}$ \\
Event* & Event of graduation & $0=$ Censored; $1=$ Graduation \\
Cohort & Cohort of enrolment & $0=2000 / 2001$ (reference), $1=2001 / 2002$, \\
& & $2=2002 / 2003,3=2003 / 2004$ \\
Mark* & Raw mark at graduation & Metric \\
Gender & Gender of the student & $0=$ Female (reference), $1=$ Male \\
Age & Age of the student at enrolment & $0=$ less or equal to 19 years old (reference), \\
& & $1=$ greater than 19 years old \\
Nationality & Nationality of the student & $0=$ Native student (reference), \\
& & $1=$ International student; \\
Country & Country of study & $0=$ Greece (reference) $1=$ Italy \\
Department & Department in which the student is & $0=$ Economics (reference), $1=$ Sociology, \\
& enrolled. & $2=$ Psychology \\
\hline
\end{tabular}

Table 1. Description of the variables in the analysis (*used to construct our main dependent variables).

The statistical modelling was carried out using R 3.5.0 (R Core Team 2018), the survival package (v2.44-1.1; Therneau and Lumley 2019) for survival analysis, the rpart package (4.1-15; Therneau and Atkinson 2019) and the mvpart package ( $\mathrm{v}$ 1.1-1; De'ath 2004) for Regression/Survival Tree and MRT respectively.

\subsection{Description of the data set}

Table 2 reports the composition of the sample with respect to the socio demographic information of students by gender. The study data consist of 10,544 students that remain students after the

\footnotetext{
${ }^{8}$ According the Italian university system the mark "110 cum laude" is considered as 113 .
} 
threshold of graduation (the beginning of the observation period) ${ }^{9}$. Sixty-nine percent of the students are women. The percentages of the Greek and Italian students in the data set are 59\% and $41 \%$ respectively. The majority of respondents (87\%) were local students. Forty-four percent of those observed were enrolled in the Economics Department, 34\% in Sociology and the remaining $22 \%$ in Psychology. Seventy-two percent of the students in the sample were considered regular students (aged less than or equal to 19 years old upon first enrolment) with the remaining 28\% of students not regular (older than 19 years at the first enrolment). Graduated students make up 79.3\% of the data set, and present an average of $T G a T$ and $G M$ of 15 months and 0.463 respectively.

\section{Results}

In this section, we present the results of the application of the above mentioned statistical methodology on the data for Gender on TGaT and GM.

\subsection{Preliminary Analysis of $T G a T$ and $G M$ by Gender}

Based on the figures in Table 2, it is clear that during the observation period the proportion of graduated women $(82 \%)$ is greater than that of men $(72 \%)$ and in fact the difference is statistically significant $\left(\chi^{2}=136.7, d f=1, p\right.$-value $\left.<0.0001\right)$. This result which is consistent with previous relevant results as described by Vincent-Lancrin (2008), supports the argument included in hypothesis I.

Also, figures concerning length of studies (Table 2), indicate that female graduated students spend on average 15 months beyond the threshold time for graduation to get their degree compared to 18 months for males, with the resulting difference being statistically significant (Kruskal-Wallis, 1952) rank sum test, $\left(\chi^{2}=216.1, d f=1, p\right.$-value $\left.<0.00001\right)$. These results are also supportive of hypothesis I where women tend to graduate earlier than men and in line with outcomes of previous studies (Trent and Ruyle, 1965; Astin, 1972; Kalamatianou and McClean, 2003; Buchmann. et al., 2008; Aina et al., 2011 and Löfgren and Ohlsson, 1999).

Examining the harmonised marks at graduation $(G M)$, women are found to have an average of 0.482 in comparison to 0.417 for men (Table 2) and this difference is again significant $\left(\chi^{2}=215.08\right.$, $d f=1, p$-value $<0.0001)$. In comparison, women have the same variation in $G M(F=0.97339$, $\mathrm{df}=5997 / 2363$; $\mathrm{p}$-value $=0.7857$ ) which also confirms our hypothesis II and agrees with McNabb et al., (2002) and Aina (2011).

\footnotetext{
${ }^{9}$ In this study we are only interested in students who are enrolled for the first time to the Universities in the study and who have remained as students beyond the graduation threshold. This study is not concerned with the students who have dropped out or who transferred to another university/department or who have left the universities due to any other causes (except graduation) during their academic life. 


\begin{tabular}{|c|c|c|c|c|c|}
\hline \multirow{2}{*}{ Variable Name } & \multirow[b]{2}{*}{ Category } & & \multicolumn{2}{|c|}{ Gender } & \multirow{2}{*}{ Total } \\
\hline & & & Female & Male & \\
\hline \multirow{8}{*}{ Cohort of entrance } & \multirow{2}{*}{$2000 / 2001$} & $\mathrm{~N}$ & 1599 & 697 & 2296 \\
\hline & & $\%$ in Gender & $22.0 \%$ & $21.3 \%$ & $21.8 \%$ \\
\hline & \multirow{2}{*}{$2001 / 2002$} & $\mathrm{~N}$ & 1958 & 849 & 2807 \\
\hline & & $\%$ in Gender & $26.9 \%$ & $26.0 \%$ & $26.6 \%$ \\
\hline & \multirow{2}{*}{$2002 / 2003$} & $\mathrm{~N}$ & 1893 & 844 & 2737 \\
\hline & & $\%$ in Gender & $26.0 \%$ & $25.8 \%$ & $26.0 \%$ \\
\hline & \multirow{2}{*}{$2003 / 2004$} & $\mathrm{~N}$ & 1829 & 875 & 2704 \\
\hline & & $\%$ in Gender & $25.1 \%$ & $26.8 \%$ & $25.6 \%$ \\
\hline \multirow{6}{*}{ Department } & \multirow{2}{*}{ Economics } & $\mathrm{N}$ & 2664 & 2009 & 4673 \\
\hline & & $\%$ in Gender & $36.6 \%$ & $61.5 \%$ & $44.3 \%$ \\
\hline & \multirow{2}{*}{ Sociology } & $\mathrm{N}$ & 2673 & 884 & 3557 \\
\hline & & $\%$ in Gender & $36.7 \%$ & $27.1 \%$ & $33.7 \%$ \\
\hline & \multirow{2}{*}{ Psychology } & $\mathrm{N}$ & 1942 & 372 & 2314 \\
\hline & & $\%$ in Gender & $26.7 \%$ & $11.4 \%$ & $21.9 \%$ \\
\hline \multirow{4}{*}{ Nationality } & \multirow{2}{*}{ Native } & $\mathrm{N}$ & 6310 & 2877 & 9187 \\
\hline & & $\%$ in Gender & $86.7 \%$ & $88.1 \%$ & $87.1 \%$ \\
\hline & \multirow{2}{*}{ International } & $\mathrm{N}$ & 969 & 388 & 1357 \\
\hline & & $\%$ in Gender & $13.3 \%$ & $11.9 \%$ & $12.9 \%$ \\
\hline \multirow{4}{*}{ Event } & \multirow{2}{*}{ Censored } & $\mathrm{n}$ & 1281 & 901 & 2182 \\
\hline & & $\%$ in Gender & $17.6 \%$ & $27.6 \%$ & $20.7 \%$ \\
\hline & \multirow{2}{*}{ Graduation } & $\mathrm{n}$ & 5998 & 2364 & 8362 \\
\hline & & $\%$ in Gender & $82.4 \%$ & $72.4 \%$ & $79.3 \%$ \\
\hline \multirow{4}{*}{ Age at enrolment } & \multirow{2}{*}{$<=19$ years old } & $\mathrm{n}$ & 5998 & 2022 & 7573 \\
\hline & & $\%$ in Gender & $76.3 \%$ & $61.9 \%$ & $71.8 \%$ \\
\hline & \multirow{2}{*}{$>19$ years old } & $\mathrm{n}$ & 1728 & 1243 & 2971 \\
\hline & & $\%$ in Gender & $23.7 \%$ & $38.1 \%$ & $28.2 \%$ \\
\hline \multirow{4}{*}{ Country } & \multirow{2}{*}{ Greece } & $\mathrm{n}$ & 4353 & 1866 & 6219 \\
\hline & & $\%$ in Gender & $59.8 \%$ & $57.2 \%$ & $59.0 \%$ \\
\hline & \multirow{2}{*}{ Italy } & $\mathrm{n}$ & 2926 & 1399 & 4325 \\
\hline & & $\%$ in Gender & $40.2 \%$ & $42.8 \%$ & $41.0 \%$ \\
\hline \multirow{2}{*}{\multicolumn{2}{|c|}{ TGaT (for 7279 graduated students) }} & Mean & 13.851 & 18.279 & 15.112 \\
\hline & & Standard Deviation & 11.545 & 12.957 & 12.129 \\
\hline \multirow{2}{*}{\multicolumn{2}{|c|}{ GM (for 7279 graduated students) }} & Mean & 0.482 & 0.417 & 0.463 \\
\hline & & Standard Deviation & 0.193 & 0.196 & 0.196 \\
\hline Total & & $\mathrm{n}$ & 7279 & 3265 & 10544 \\
\hline & & $\%$ on Total & $69.0 \%$ & $31.0 \%$ & $100.0 \%$ \\
\hline
\end{tabular}

Table 2. Description of the variables in the data set by gender.

\subsection{Survival Analysis Results of TGaT}

Figures 3(a) and 3(b) provide the survival function of TGaT estimated using the Kaplan-Meier approach (according to eq. 3) for the full data set and for men and women respectively.

When considering the full data set, it can be seen that the median TGaT (Figure 3(a), $S(t)=0.5$ ) and the upper quartile (Figure $3(\mathrm{a}), \mathrm{S}(t)=0.25$ ) are approximately 16 and 39 months respectively, 
suggesting that a quarter of the students have not graduated almost three years after the threshold. When considering the women and men, it can be seen (Figure 3(b)) that the graduation rate in general is lower for men for each $t$ time, compared to women. This difference is proven significant according to the log-rank test $(z=-16.822, p$-value $<0.00001)$ hence suggesting a different behaviour between women and men with respect to TGaT. This is also supported by information given in Table 3 concerning graduation times, the risk (probability) of a student not graduating in one, two or three years after the threshold for graduation and the estimated risk (probability) of a student not yet graduating after 4 years (calculated according to eq. 4). The median $T G a T$ for women is 14 compared to 24 months for men, while the previously mentioned probabilities of not graduating are continually lower for women in comparison to men. All of these results indicate a better performance for women regarding TGaT, hence verifying hypothesis I.
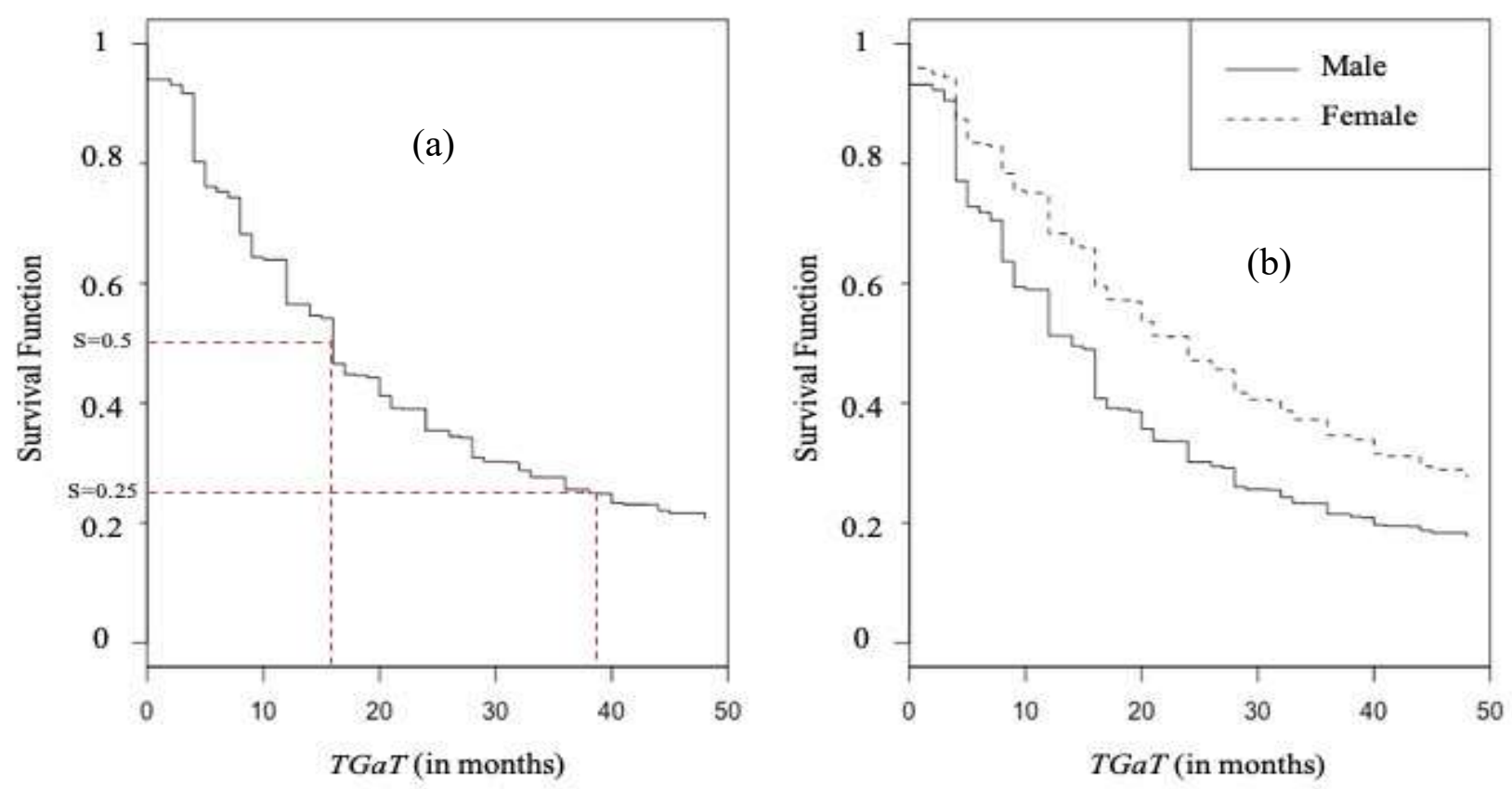

Figure 3. Kaplan-Meier estimates for TgaT.

\begin{tabular}{lccccc}
\hline & Median & \multicolumn{4}{c}{ Probability not graduated after } \\
\cline { 3 - 6 } & TGaT & 1 Year & 2 Years & 3 Years & 4 Years \\
\hline Female & 14 & $0.513(0.006)$ & $0.302(0.005)$ & $0.215(0.005)$ & $0.176(0.004)$ \\
Male & 24 & $0.683(0.008)$ & $0.471(0.009)$ & $0.346(0.008)$ & $0.276(0.008)$ \\
Total & 16 & $0.565(0.005)$ & $0.354(0.005)$ & $0.256(0.004)$ & $0.207(0.004)$ \\
\hline
\end{tabular}

Table 3. Kaplan-Meier estimates of TGaT by Gender (standard errors in parentheses).

Given that the TGaT is highly related to Gender, it is interesting to enrich the information by incorporating the estimated Kaplan-Meier survival function into the GPI (first given in eq. 6) as follows: 


$$
G P I_{t}=\frac{S(t)_{F}}{S(t)_{M}}
$$

Recall, that a value of less than 1 of GPI, indicates a disparity in favour of women and precisely that at time $t$ the proportion of "survived" women (still studying) is less than that of men. Obviously, the opposite holds if GPI has a value greater than 1. In Figure 4, the results on the GPIt are reported with respect to the total sample and taking into account the variables: Cohort of entrance, Department, Nationality, Age at enrolment and Country.

In summary, GPI $I_{t}$ has a value lower than 1 for all $t$, highlighting a disparity in favour of women. Moreover, it can be seen that the shape of the $G P I_{t}$ curve is constantly decreasing in the first 20 months of the observation period then it decreases slowly and finally stabilizes to 0.6 after 30 months. This means that the proportion of graduating women is always greater than that of men. However, it comes out that during the first 30 months of the observation period the difference in these proportions is getting greater, month by month, in favour of women, and then remains constant. One explanation for this graduation behaviour could be that women are more strongly committed to fulfil their studies and get their degree particularly at the beginning of the observation period.
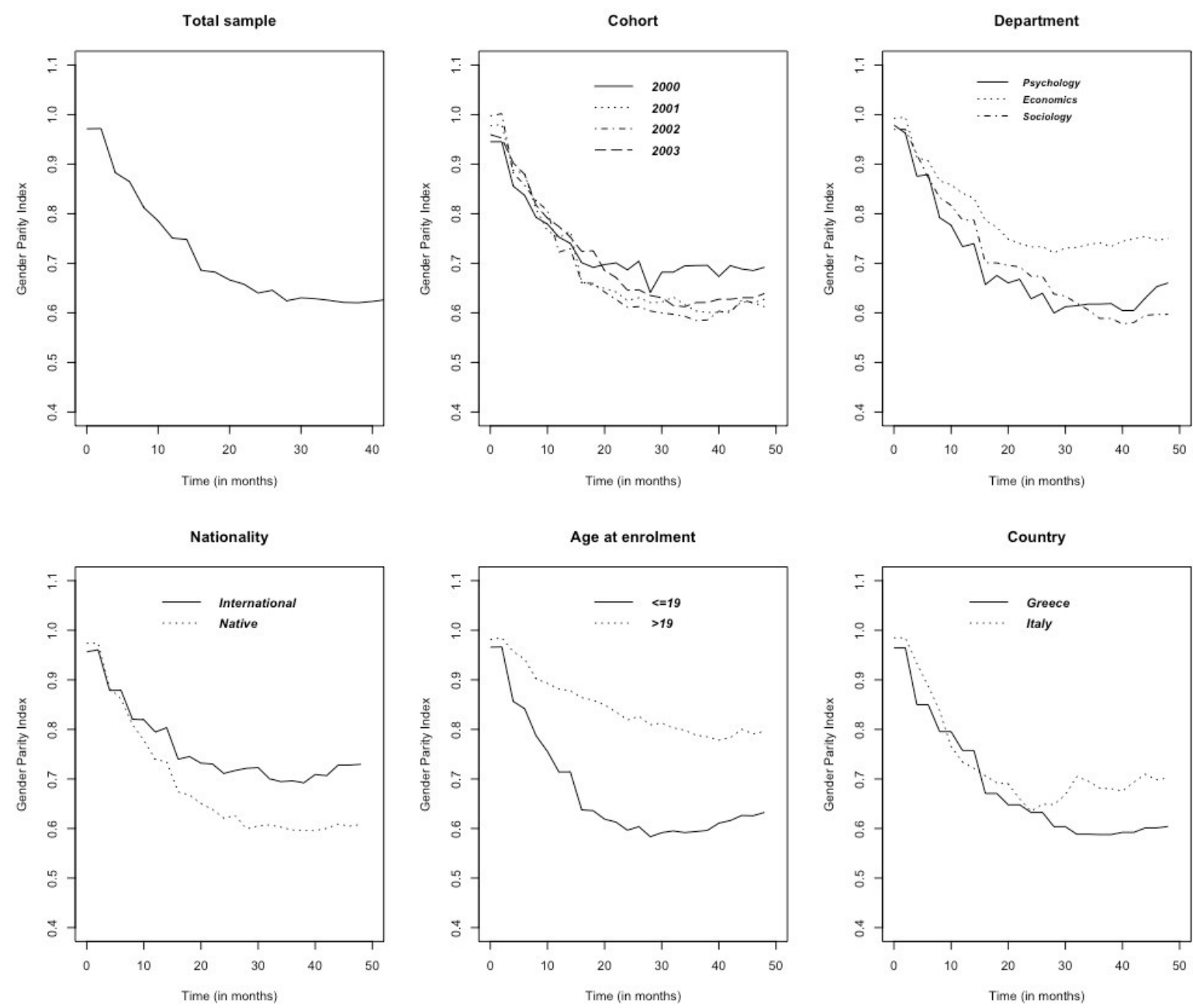

Figure 4. GPI $I_{t}$ for the total sample considering the variables; cohort of entrance, department, nationality, student age at enrolment and country. 
The results for GPI taking into account the previously mentioned covariates (Figure 4) are generally in line with the results presented previously. In particular, $G P I_{t}$ figures show that there is disparity in favour of women in all departments but more pronounced for women in Sociology and Psychology. We note that as mentioned in Mullen and Backer (2018), women are stronger in traditional female-dominated departments such as Psychology and Sociology, than in maledominated, such as Business and Economics. When considering the nationality and age at enrolment, GPIt figures show that the native students have greater disparity for women in comparison to the international (non-native) students, and the regular students have greater disparity for women in comparison to non-regular students. Yet, when considering country $G P I_{t}$ figures show that for the first 24 months there is the same trend in disparity in favour of women for both Italian and Greek students however beyond this point the disparity for the two countries widens. In conclusion, all of the results concerning $G P I_{t}$ also confirm hypothesis I.

Further analysis investigates how the explanatory variables contribute to the $T G a T$ variation. Due to the nature of TGaT which includes censoring, we fit several accelerated failure time regression models (AFT), according to eq. 5. The results in Table 4 provide the goodness of fit measures for the models. Looking at the values of AIC and BIC (Schwarz 1978), the Weibull accelerated failure time model appears to be the more appropriate, having scored the lowest in all metrics.

\begin{tabular}{lcccc}
\hline & \multicolumn{3}{c}{ Accelerated failure time models } \\
\cline { 2 - 5 } & Exponential & Weibull & Log-normal & Log-logistic \\
\hline Log-likelihood & -35305.05 & -34096.14 & -37264.79 & -35220.95 \\
AIC & 70630.1 & 68214.28 & 74551.58 & 70463.91 \\
BIC & 70702.73 & 68294.18 & 74631.47 & 70543.8 \\
\hline
\end{tabular}

Table 4. The comparison among several failure time models.

Table 5 reports for the total data set the estimates of the Weibull AFT regression coefficients corresponding to the explanatory variables of TGaT where it appears that Gender, Age, Nationality, Country and Department have a significant impact. In particular, TGaT for men is expected to be about $46 \%(=(\exp (0.376)-1) \cdot 100)$ more than women, keeping all other variables constant. In Table 6 we explore two separate AFT models for men and women for the purpose of investigating this gender gap and compare the effect of the covariates between men and women separately and for the full data set. At a first glance, we observe that the coefficients of the female and male models in table 6 have similar signs to those in table 5 meaning that these covariates contribute in the same way to TGaT. Focusing on the differences in the models corresponding to men and women, we found that the Department, Age, Nationality and Country show significant 20 
differences in the magnitude of the corresponding coefficients. For the model for women, it appears that the covariates with most impact on TGaT, in order, are Age, Department, Nationality, and Country, in comparison for the model for men where it appears that the covariates with most impact on TGaT are the same, in a different order of Country, Age, Department and Nationality, however in all cases the covariates have a higher impact on women than on men.

\begin{tabular}{lccccc}
\hline Variable/Parameter & $\begin{array}{c}\text { Estimate } \\
\text { (Est) }\end{array}$ & $\begin{array}{c}\text { Standard } \\
\text { Error }\end{array}$ & $z$ & $p$-value & exp (Est) \\
\hline (Intercept) & 3.263 & 0.047 & 69.982 & $<0.00001$ & 26.135 \\
Male & 0.376 & 0.039 & 9.569 & $<0.00001$ & 1.456 \\
Cohort: $2001 / 2002$ & 0.041 & 0.052 & 0.803 & 0.422 & 1.042 \\
Cohort:2002/2003 & 0.157 & 0.050 & 3.157 & $<0.00001$ & 1.170 \\
Cohort:2003/2004 & 0.199 & 0.051 & 3.945 & $<0.00001$ & 1.220 \\
Sociology & -0.366 & 0.041 & -8.939 & $<0.00001$ & 0.694 \\
Psychology & -0.508 & 0.045 & -11.179 & $<0.00001$ & 0.602 \\
International students & 0.391 & 0.062 & 6.341 & $<0.00001$ & 1.478 \\
Age $>=19$ years & 0.581 & 0.040 & 14.362 & $<0.00001$ & 1.787 \\
Italy & -0.433 & 0.037 & -11.639 & $<0.00001$ & 0.649 \\
W & 0.441 & 0.010 & 44.581 & $<0.00001$ & 1.554 \\
\hline Loglik(model) & -34096.1 & & & & \\
Loglik (intercept only) & -34516.8 & & & & \\
LR $\chi^{2}$ & 841.34 & & & & \\
Df & 9 & & & & \\
Prob> $\chi^{2}$ & $<0.00001$ & & & & \\
\hline
\end{tabular}

Table 5. Results of the Weibull accelerated failure time regression model for the full data set.

To further clarify the above results, we fit a survival tree to the data to identify groups of students who behave similarly with respect to $T G a T$ taking into account the covariates. Figure 5 summarises the results where Gender shows the greatest level of importance (40.7\%), followed by Department (39.3\%), Age (10.5\%), Nationality (8.4\%) and Country (6.4\%). The proportion of variance of $T G a T$ that is explained by the survival tree is $51 \%$ which can be considered a sufficient model. 


\begin{tabular}{|c|c|c|c|c|c|c|c|c|c|c|}
\hline & \multicolumn{4}{|c|}{ Female students } & \multicolumn{4}{|c|}{ Male students } & \multicolumn{2}{|r|}{$\Delta$} \\
\hline & $\begin{array}{l}\text { Estimate } \\
\text { (Est) }\end{array}$ & $\begin{array}{l}\text { Standard } \\
\text { Error }\end{array}$ & $p$-value & $\exp (E s t)$ & $\begin{array}{l}\text { Estimate } \\
\text { (Est) }\end{array}$ & $\begin{array}{l}\text { Standard } \\
\text { Error }\end{array}$ & $p$-value & $\exp (E s t)$ & $\begin{array}{l}\text { Est.- } \\
\text { Est }_{\mathrm{M}}\end{array}$ & $p$-value \\
\hline (Intercept) & 3.231 & 0.056 & $<0.00001$ & 25.308 & 3.767 & 0.075 & $<0.00001$ & 43.230 & $0 . \overline{-} 35$ & $<0.00001$ \\
\hline $\begin{array}{l}\text { Cohort: } \\
\text { 2001/2002 }\end{array}$ & 0.027 & 0.063 & 0.673 & 1.027 & 0.056 & 0.086 & 0.516 & 1.058 & $0 . \overline{0} 9$ & 0.392 \\
\hline $\begin{array}{l}\text { Cohort: } \\
\text { 2002/2003 }\end{array}$ & 0.164 & 0.062 & 0.008 & 1.178 & 0.111 & 0.082 & 0.173 & 1.118 & 0.053 & 0.303 \\
\hline $\begin{array}{l}\text { Cohort: } \\
\text { 2003/2004 }\end{array}$ & 0.194 & 0.063 & 0.002 & 1.214 & 0.165 & 0.082 & 0.045 & 1.179 & 0.029 & 0.389 \\
\hline Sociology & -0.404 & 0.051 & $<0.00001$ & 0.668 & -0.284 & 0.068 & $<0.00001$ & 0.753 & -0.12 & 0.079 \\
\hline Psychology & -0.556 & 0.054 & $<0.00001$ & 0.573 & -0.343 & 0.088 & 0.0001 & 0.710 & $0 . \overline{214}$ & 0.020 \\
\hline $\begin{array}{l}\text { International } \\
\text { students }\end{array}$ & 0.421 & 0.074 & $<0.00001$ & 1.524 & 0.292 & 0.109 & 0.007 & 1.339 & 0.129 & 0.164 \\
\hline Age $>=19$ years & 0.669 & 0.053 & $<0.00001$ & 1.953 & 0.368 & 0.061 & $<0.00001$ & 1.444 & 0.301 & $<0.00001$ \\
\hline Italy & -0.342 & 0.046 & $<0.00001$ & 0.710 & -0.646 & 0.062 & $<0.00001$ & 0.524 & 0.303 & $<0.00001$ \\
\hline W & 0.486 & 0.012 & $<0.00001$ & 1.626 & 0.307 & 0.019 & $<0.00001$ & 1.360 & 0.179 & $<0.00001$ \\
\hline Loglik(model) & -23522.3 & & & & -10527.8 & & & & & \\
\hline $\begin{array}{l}\text { Loglik (intercept } \\
\text { only) }\end{array}$ & -23737.5 & & & & -10645.2 & & & & & \\
\hline $\operatorname{LR} \chi^{2}$ & 430,52 & & & & 234.82 & & & & & \\
\hline Df & 8 & & & & 8 & & & & & \\
\hline Prob $>\chi^{2}$ & $<0.00001$ & & & & $<0.00001$ & & & & & \\
\hline
\end{tabular}

Table 6. Results of the Weibull accelerated failure time regression model for women and men.

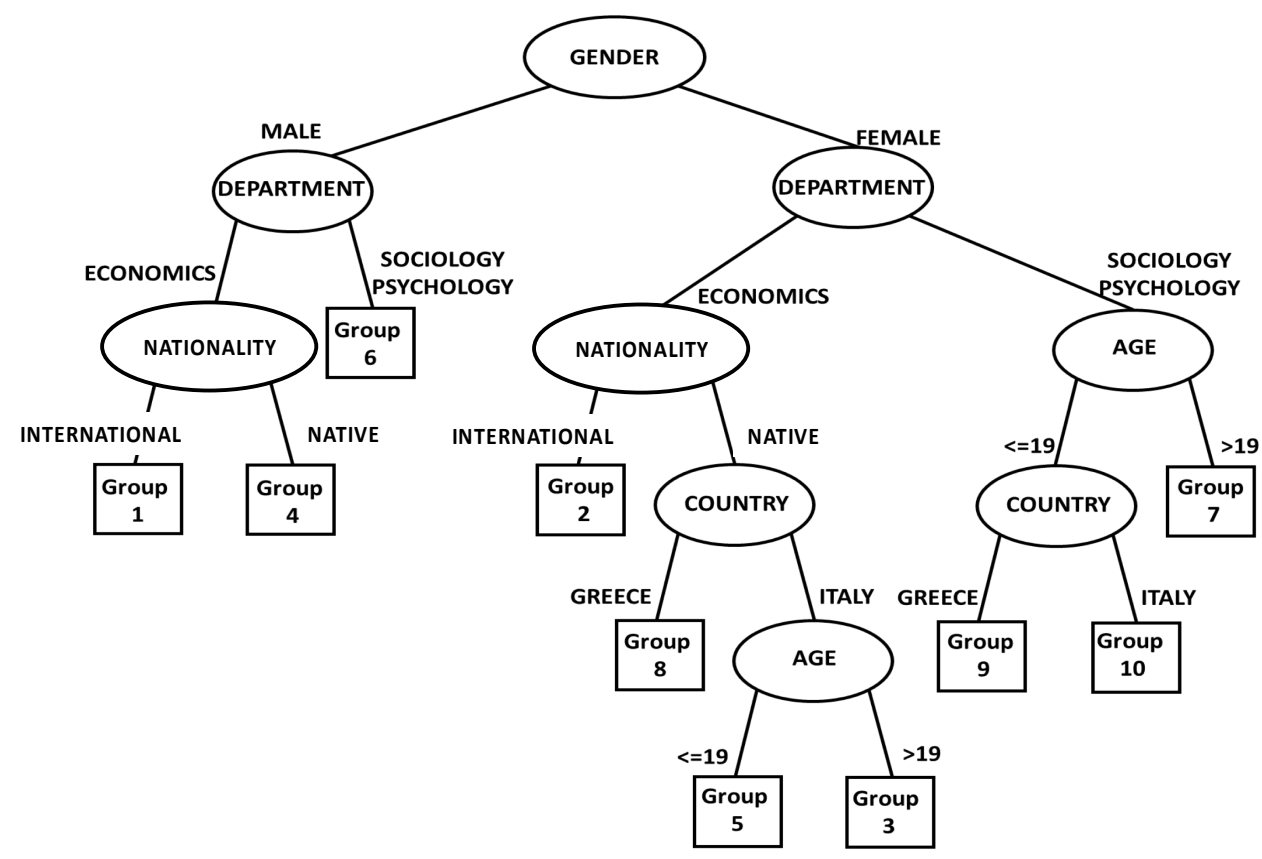

Figure 5. The survival tree for students by TGaT. 


\begin{tabular}{|c|c|c|c|c|c|}
\hline Group & Description & $\mathrm{n}$ & $\begin{array}{c}\% \\
\text { Graduated }\end{array}$ & $\begin{array}{c}\% \\
\text { Censored }\end{array}$ & $\begin{array}{c}\text { Median } \\
T G a T\end{array}$ \\
\hline 1 & $\begin{array}{l}\text { Men, Economics, } \\
\text { International Student }\end{array}$ & 264 & 58.33 & 41.67 & 40 \\
\hline 2 & $\begin{array}{l}\text { Women, Economics, } \\
\text { International Student }\end{array}$ & 431 & 61.25 & 38.75 & 32 \\
\hline 3 & $\begin{array}{l}\text { Women, Economics, } \\
\text { Native, Italy, Age }>19\end{array}$ & 165 & 70.30 & 29.70 & 24 \\
\hline 4 & $\begin{array}{l}\text { Men, Economics, } \\
\text { Native }\end{array}$ & 1745 & 74.10 & 25.90 & 24 \\
\hline 5 & $\begin{array}{l}\text { Women, Economics, } \\
\text { Native, Italy, Age } \leq 19\end{array}$ & 851 & 90.36 & 9.64 & 17 \\
\hline 6 & $\begin{array}{l}\text { Men, Sociology \& } \\
\text { Psychology }\end{array}$ & 1256 & 73.01 & 26.99 & 17 \\
\hline 7 & $\begin{array}{l}\text { Women, Sociology \& } \\
\text { Psychology, Age }>19\end{array}$ & 1201 & 74.02 & 25.98 & 16 \\
\hline 8 & $\begin{array}{l}\text { Women, Economics, } \\
\text { Native, Greece }\end{array}$ & 1217 & 78.55 & 21.45 & 16 \\
\hline 9 & $\begin{array}{l}\text { Women, Sociology \& } \\
\text { Psychology, Age } \leq 19 \text {, } \\
\text { Greece }\end{array}$ & 2034 & 82.20 & 17.80 & 12 \\
\hline 10 & $\begin{array}{l}\text { Women, Sociology \& } \\
\text { Psychology, Age } \leq 19 \text {, } \\
\text { Italy }\end{array}$ & 1380 & 96.52 & 3.48 & 9 \\
\hline
\end{tabular}

The terminal nodes of the tree identified 10 homogeneous groups described in Table 7 . The first group is associated with a TGaT (in median) equal to 40 months consisting of 264 male international students in Economics of which 58\% have graduated. In terms of median TGaT, this group has the lowest performance, which may underline a particular difficulty for international students when they study abroad. The second group consists of 431 female international students in Economics with a median TGaT of 32 months (eight months less than the first group) of which $61.5 \%$ have graduated. This group performs better than the first in terms of TGaT (20\% lower) and graduation rate $(5 \%$ higher) and differs only by gender suggesting that when all other variables remain constant (Economics and Nationality) the female students are more resilient than the males. The third group consists of 165 native non-regular female Italian students whose median TGaT is 24 months and graduation rate is approximately 70\%. The fourth group comprises of 1745 native male students in Economics with a median TGaT of 24 months and a graduation rate of $74.10 \%$. Group 5 consists of 851 regular native female students in Economics with median TGaT of 17 
months and graduation rate of 90.36\%. Group 6 are 1256 male students in Psychology or Sociology with median TGaT of 17 months and a graduation rate of 73\%. The 1201 non-regular female students in Sociology and Psychology compose the seventh group that have a median TGaT of 16 months and a graduation rate of $74 \%$. The 1217 native Greek students in Economics, the eighth group, present a median $T G a T$ of 16 months and graduation rate of $78.6 \%$. The last two groups are correspondingly for 2034 Greek and 1380 Italian women in with corresponding median TGaTs of 12 and 9 months and graduation rates of $82.2 \%$ and $96.5 \%$ respectively.

In summary, the results of the decision tree analysis show that the women perform better than their men. This is reinforced with the development of 10 groups of student behaviour where only three of the groups correspond to men who tend to be less influenced by other characteristics. All of this verifies hypothesis I.

\subsection{The Gender Effect on the $G M$}

The analysis in this section concerns the 8362 graduated $^{10}$ students (5998 women and 2364 men). Table 8 reports statistics on the harmonised graduation mark $(G M)$ for the total sample and considering the covariates. It is apparent that female students are doing better in terms of $G M$, in particular, the women have a statistically significant higher average $G M$ with lower standard deviation than those of men. The results are similar taking into account Department, Country, Age and Nationality. These results confirm our hypothesis II on the performance in GM and they are consistent with the results of McNabb et al. (2002).

Table 9 reports the mean and standard deviation of $G M$ with respect to $T G a T$ values. According to the figures, the main result shows that the greater the average $G M$, the less the $T G a T$, meaning that students who graduate faster (closer to the threshold of graduation) get better $G M$ scores and exhibit more homogeneity in $G M$, according to Coefficient of Variation $(\mathrm{CV})^{11}$ figures.

Further analysis of the GPI modified appropriately for GM $\left(G P I_{G M}=\frac{G M_{F, t}}{G M_{M, t}}\right)$ assumes that for each class of TGaT a value greater than 1 indicates a disparity in $G M$ in favour of females (measured in intervals of TGaT in Table 10). In particular, it is apparent that $G P I_{G M}$ increases as TGaT increases and that holds in almost all cases taking into account the covariates. These results strongly support hypothesis II.

\footnotetext{
${ }^{10}$ To analyze the GM, we must consider only students that graduated during the observation period.

${ }^{11} \mathrm{CV}=\frac{\text { Std.Dev }}{\text { Mean }}$ 


\begin{tabular}{|c|c|c|c|c|c|c|c|c|c|c|}
\hline & \multicolumn{2}{|c|}{ GM Mean } & \multicolumn{3}{|c|}{$\begin{array}{c}\text { Test on Mean } \\
\text { (null hypothesis: } \\
\pi_{F E M}=\pi_{M A L} \text { ) }\end{array}$} & \multicolumn{2}{|c|}{$\begin{array}{l}\text { GM Standard } \\
\text { Deviation }\end{array}$} & \multicolumn{3}{|c|}{$\begin{array}{c}\text { Test on Variance } \\
\text { (null hypothesis: } \sigma_{F E M}^{2}=\sigma_{M A L}^{2} \text { ) }\end{array}$} \\
\hline & Female & Male & t-stat & $\mathrm{df}^{*}$ & $p$-value & Female & Male & F-stat & $\mathrm{df}^{*}$ & $p$-value \\
\hline $\begin{array}{l}\text { Total } \\
\text { sample }\end{array}$ & 0.4816 & 0.4173 & 13.659 & 8360 & $<0.0001$ & 0.193 & 0.196 & 0.97339 & $5597 / 2363$ & 0.2143 \\
\hline Economics & 0.458 & 0.401 & 8.217 & 3551 & $<0.0001$ & 0.206 & 0.200 & 1.0525 & $2104 / 1447$ & 0.8541 \\
\hline Sociology & 0.452 & 0.427 & 3.049 & 2791 & 0.0012 & 0.178 & 0.185 & 0.92335 & $2181 / 610$ & 0.1052 \\
\hline Psychology & 0.548 & 0.474 & 6.618 & 2014 & $<0.0001$ & 0.179 & 0.182 & 0.9703 & $1710 / 304$ & 0.3594 \\
\hline Greece & 0.422 & 0.357 & 12.046 & 4505 & $<0.0001$ & 0.157 & 0.162 & 0.93179 & $3350 / 1155$ & 0.0694 \\
\hline Italy & 0.557 & 0.475 & 11.402 & 3853 & $<0.0001$ & 0.208 & 0.207 & 1.0053 & $2646 / 1207$ & 0.5404 \\
\hline$<=19$ years & 0.486 & 0.420 & 11.582 & 6337 & $<0.0001$ & 0.194 & 0.199 & 0.9445 & $4767 / 1570$ & 0.08069 \\
\hline$>19$ years & 0.464 & 0.411 & 6.140 & 2021 & $<0.0001$ & 0.190 & 0.189 & 1.0162 & $1229 / 792$ & 0.5965 \\
\hline Native & 0.490 & 0.424 & 13.178 & 7463 & $<0.0001$ & 0.195 & 0.198 & 0.97237 & $53257 / 2138$ & 0.2176 \\
\hline Foreigner & 0.412 & 0.352 & 4.973 & 895 & $<0.0001$ & 0.157 & 0.156 & 1.01 & $671 / 224$ & 0.5291 \\
\hline
\end{tabular}

Table 8. Statistics on GM for graduated students (*df-degrees of freedom).

\begin{tabular}{lcccccccccccccc}
\hline & \multicolumn{4}{c}{ Female } & \multicolumn{4}{c}{ Male } & \multicolumn{4}{c}{ Total sample } \\
\cline { 2 - 5 } & $n$ & Mean & $\begin{array}{c}\text { Standard } \\
\text { Deviation }\end{array}$ & CV $^{*}$ & $n$ & Mean & $\begin{array}{c}\text { Standard } \\
\text { Deviation }\end{array}$ & CV & $n$ & Mean & $\begin{array}{c}\text { Standard } \\
\text { Deviation }\end{array}$ & CV \\
\hline $0-12$ & 3548 & 0.54 & 0.19 & 0.34 & 1037 & 0.503 & 0.20 & 0.40 & 4585 & 0.53 & 0.19 & 0.36 \\
$13-24$ & 1535 & 0.42 & 0.17 & 0.41 & 690 & 0.384 & 0.16 & 0.42 & 2225 & 0.41 & 0.17 & 0.41 \\
$25-36$ & 630 & 0.37 & 0.17 & 0.46 & 408 & 0.329 & 0.16 & 0.49 & 1038 & 0.35 & 0.17 & 0.47 \\
$37-48$ & 285 & 0.33 & 0.15 & 0.47 & 229 & 0.286 & 0.16 & 0.57 & 514 & 0.31 & 0.16 & 0.51 \\
Total & 5998 & 0.48 & 0.19 & 0.41 & 2364 & 0.41 & 0.20 & 0.48 & 8362 & 0.46 & 0.20 & 0.43 \\
\hline
\end{tabular}

Table 9: Mean and variation of GM with respect to TGaT.

\begin{tabular}{|c|c|c|c|c|c|c|c|c|c|c|c|c|c|c|}
\hline \multirow{3}{*}{$T G a T$} & \multicolumn{14}{|c|}{$G P I$} \\
\hline & \multirow{2}{*}{$\begin{array}{c}\text { Total } \\
\text { sample }\end{array}$} & \multicolumn{4}{|c|}{ Cohort } & \multicolumn{3}{|c|}{ Department } & \multicolumn{2}{|c|}{ Nationality } & \multicolumn{2}{|c|}{ Age } & \multicolumn{2}{|c|}{ Country } \\
\hline & & 2001 & 2002 & 2003 & 2004 & Econom. & Soc. & Psyc. & Intern. & Native & $<=19$ & $>19$ & Greece & Italy \\
\hline $0-12$ & 1.072 & 1.098 & 1.049 & 1.088 & 1.065 & 1.058 & 1.044 & 1.090 & 1.033 & 1.080 & 1.054 & 1.086 & 1.083 & 1.092 \\
\hline $13-24$ & 1.099 & 1.065 & 1.094 & 1.087 & 1.157 & 1.099 & 1.047 & 1.169 & 1.108 & 1.101 & 1.083 & 1.127 & 1.157 & 1.118 \\
\hline $25-36$ & 1.112 & 0.973 & 1.216 & 1.050 & 1.276 & 1.072 & 0.967 & 1.100 & 1.246 & 1.104 & 1.137 & 1.063 & 1.223 & 1.100 \\
\hline $37-48$ & 1.157 & 1.093 & 1.083 & 1.262 & 1.270 & 1.160 & 0.995 & 0.987 & 1.119 & 1.172 & 1.167 & 1.145 & 1.190 & 1.129 \\
\hline
\end{tabular}

Table 10. GPI for GM. 


\subsection{The Gender Effect jointly on $G M$ and $T G a T$}

Advancing the previous analysis, we apply the MRT approach to detect homogeneous groups with respect to the observed TGaT and GM together and thus testing hypothesis III. The idea is that some groups of students who are more committed than others to their study and development at the University have behaviours that are reflected on $T G a T$ and $G M$ at the same time. Note that $T G a T$ and $G M$ together are important criteria for employers and this fact makes them also important indicators for evaluating Universities performance. In this context, it is important to examine the gender effect jointly on GM and TGaT (Lombardo and Passarelli, 2011).

The resulting multivariate regression tree is illustrated in Figure 6 representing the TGaT and $G M$ according to the students' characteristics. The proportion of variance in $T G a T$ and $G M$ combined that is explained by the model is $48 \%$, which indicates a fairly sufficient model. The terminal nodes of the tree identified eight homogeneous groups described in Table 11. The variables with highest relative importance are Department (54.16\%), Gender (19.25\%), Age (7.54\%), Nationality (7.41\%), Cohort (6,21\%) and Country (5.42\%).

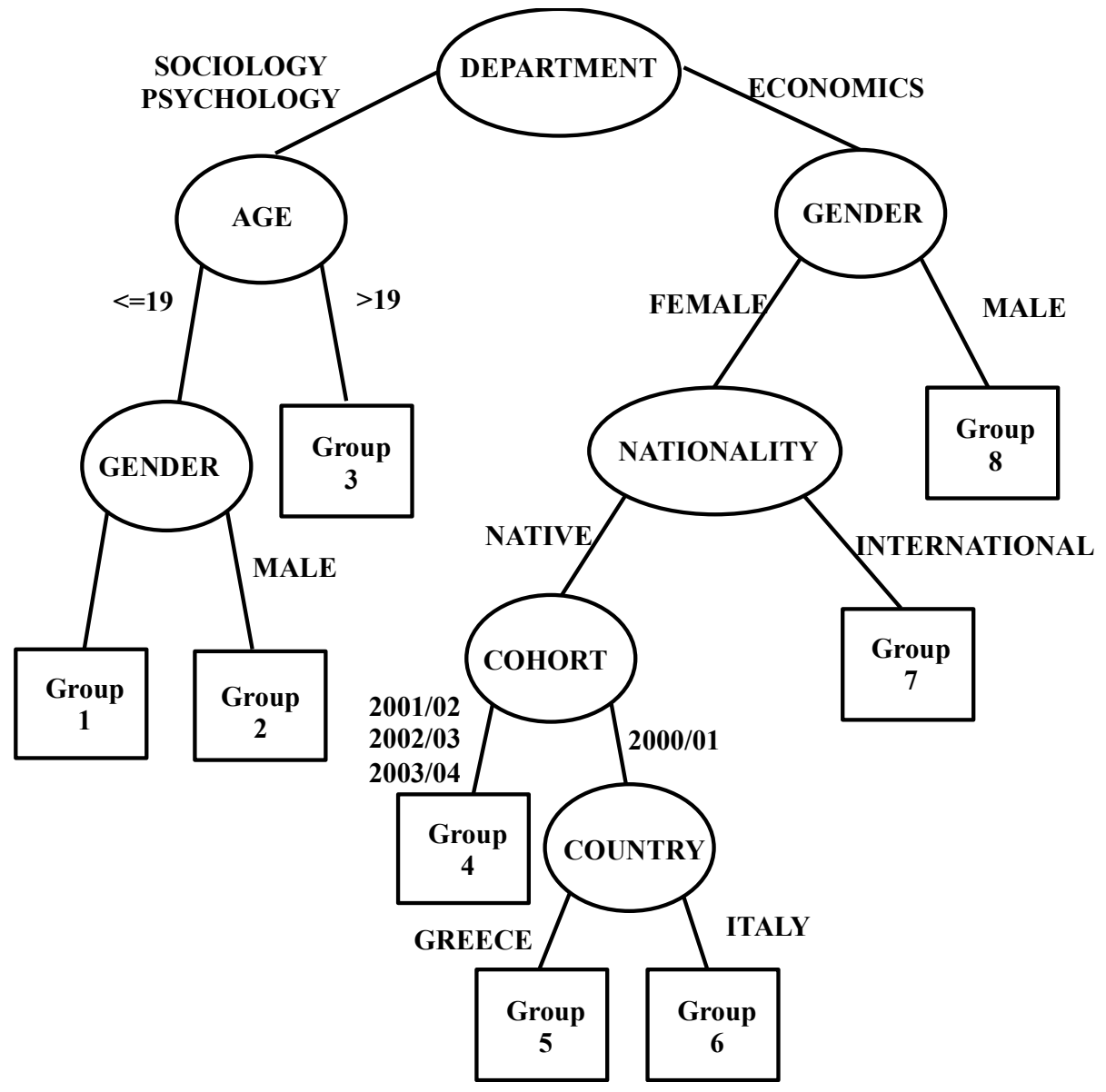

Figure 6. The regression tree for students by TGaT and GM.

The first group is associated with the lowest $T G a T$ and highest GM consisting of 3004 regular female students in Sociology and Psychology who spend on average 12 months until graduation (after the threshold) and have an average graduation mark of 0.497 ; these students define the 26 
highest performing group. The second group consists of 505 regular male students in Sociology and Psychology, who have a TGaT of 16.73 months and a $G M$ of 0.444 .

\begin{tabular}{|c|c|c|c|c|c|}
\hline Group & Description & $n$ & $\%$ & Mean $(T G a T)$ & Mean $(G M)$ \\
\hline 1 & $\begin{array}{l}\text { Sociology/ Psychology, } \\
<=19 \text { years, Women }\end{array}$ & 3004 & 35.92 & 12.244 & 0.497 \\
\hline 2 & $\begin{array}{l}\text { Sociology/ Psychology, } \\
<=19 \text { years, Men }\end{array}$ & 505 & 6.04 & 16.727 & 0.444 \\
\hline 3 & $\begin{array}{l}\text { Sociology/ Psychology. } \\
>19 \text { years }\end{array}$ & 1300 & 15.55 & 16.097 & 0.463 \\
\hline 4 & $\begin{array}{l}\text { Economics, Women, } \\
\text { Native, } \\
\text { Cohort 2001/2002/2003 }\end{array}$ & 1290 & 15.43 & 16.124 & 0.483 \\
\hline 5 & $\begin{array}{l}\text { Economics, Women, } \\
\text { Native, Cohort 2000, } \\
\text { Greece }\end{array}$ & 347 & 4.15 & 15.342 & 0.387 \\
\hline 6 & $\begin{array}{l}\text { Economics, Women, } \\
\text { Native, Cohort 2000, Italy }\end{array}$ & 204 & 2.44 & 25.156 & 0.523 \\
\hline 7 & $\begin{array}{l}\text { Economics, Women, } \\
\text { Foreign }\end{array}$ & 264 & 3.57 & 23.262 & 0.329 \\
\hline 8 & Economics, Men & 1448 & 17.32 & 22.103 & 0.391 \\
\hline
\end{tabular}

Table 11. Description of the eight groups identified by multivariate regression tree on TGaT and GM.

The third group consists of non-regular students in Sociology and Psychology, independent of gender with average TGaT of 16 months and GM of 0.463 . The fourth group consists of native female students enrolled in the second, third and last cohort of entrance in Economics who have an average $T G a T$ of 16.124 months with a $G M$ of 0.483 . The fifth group, consists of native Greek female students enrolled in the first cohort year, with average TGaT of 15.3 months and GM of 0.387. The sixth group consists of native Italian female students who have an average TGaT of 25.156 months and a $G M$ of 0.523 . The seventh group consists of international female students in Economics who have an average TGaT of 23.262 months with the lowest GM of 0.329 . The last group (the eighth), consists of 1448 male students in Economics whose average TGaT is 22.103 months and $G M$ is 0.391 .

In general, when it is possible to make comparisons directly between two groups composed with the same categories except for gender, the results show women are more effective in terms of TGaT and GM. Hence, the MRT groups provide evidence to support hypothesis III that male students who complete their studies in a similar time to female students have a lower graduation mark than their female counterparts, and add further evidence to support hypotheses I and II. 


\section{Conclusions}

Given women have outperformed men in terms of enrolment and graduation indicators in higher education, this paper has conducted an in-depth analysis of further indicators to explore the gender gap in the intermediate stage. The investigation concerns the more refined variables of the length of studies and the student's final graduation mark which are considered two very strong important indicators for employers and in evaluating universities today. The paper was motivated by examining the data sets concerning the progress of students enrolled in social science-oriented departments in an Italian and Greek University. Both Universities have a common feature where students have a minimum time requirement to study but no upper limit by which the studies should be completed. However, our proposed methodology could be useful to investigate similar indicators in any level of education.

Our objectives are summarised in three hypotheses concerning gender and how it relates to length of studies and graduation marks considering other characteristics of the students which are age at enrolment, cohort, nationality and department. For this particular piece of work, we define the two main dependent variables as the indicators: Time to Graduation after Threshold (TGaT) and harmonised Graduation Mark (GM) for students.

To respond to the nature of our data that involves censoring as well as address the questions under investigation, the statistical approach utilised in the analysis uniquely combines survival analysis with data mining approaches. Specifically, the methods include survival analysis and in particular Kaplan-Meier estimators for capturing the probability of a student to have a length of studies greater than time $t$, accelerated failure time models for capturing the effect of other variables on the length of studies and performance at the University and regression trees (survival tree and multivariate regression trees) to highlight student characteristics that influence TGaT and GM. The analysis is enriched, in all cases of the investigation, by introducing a modified version of an inequality index between genders, used by UNESCO (2017), to represent the differences in gender parity. To the best of the authors' knowledge, this methodology has not been used before in analysing this type of scenario.

This methodology successfully identifies similar relationships as reported in the literature and verifies our hypotheses, the results of which are summarised as follows. The main conclusion is that women perform better concerning these two indicators TGaT and GM.

In particular, by performing survival analysis on $T G a T$ our results confirm previous research that there is a significant difference in male and female students with women graduating on average earlier than men. Upon conducting a Weibull accelerated failure time model, it can be argued that Gender, Age, Nationality, Country and Department appear to have a significant impact on TGaT. To refine this further, separate Weibull AFT models were fitted to the data for each gender, 28 
controlling for other student characteristics, where it has been found again gender disparity in favour of women, with some covariates emphasizing this gap. In particular, belonging to a Department in the social field (as Sociology or Psychology), being a native or a regular student accentuates the difference in favour of female. These findings are highlighted in the results obtained by the survival tree and multivariate regression tree analyses where gender is dominant in establishing different groups of student behaviour. In all of the above stages, the GPI results verify that women outperform men regarding these two main indicators and taking into account other covariates.

For $G M$, the results produced, mainly through multivariate regression trees and GPI, are also consistent with the previous studies where female students perform better on average when controlling for the covariates. In summary, $G P I_{G M}$ increases as $T G a T$ increases hence demonstrating the gender disparity according to length of studies. Furthermore, when analysing jointly $T G a T$ and $G M$, it is evident that the female groups are more effective with lower $T G a T$, lower graduation time and better GM. To conclude, the results of the analysis provide strong evidence to support the use of the $T G a T$ and $G M$ as higher education indicators and confirms that women outperform men with respect to performance.

The results from this study underline gender differences in graduation in favour of female students, in three socio-economics departments for two public universities in Greece and Italy, however, there are a few limitations with regard to the data. First, a number of variables of interest were not present in the data set, for example variables regarding the pre-university characteristics of students or variables of the students on the financial aid, health issues, family needs, jobs, and other life events during the university. Second, our considerations are related to social-sciences oriented departments. There are alternative studies that demonstrate that a gender gap in favour of male students in STEM faculties remains a persistent issue despite increased efforts to understand it. As a further work, it would be interesting to explore this avenue of research, data permitting.

\section{REFERENCES}

Aina, C. (2011) The Determinants of Success and Failure of Italian University Students. Evidence from administrative data. Rivista internazionale di scienze sociali, 2, 1-24.

Aina, C., Baici, E., \& Casalone, G., (2011), Time to degree: students' abilities, university characteristics or something else? Evidence from Italy. Education Economics, 19(3), 311-325

Aina, C., Baici, E., Casalone, G., \& Pastore, F. (2018) The Economics of University Dropouts and Delayed Graduation: A Survey, IZA Discussion Paper n. 11421, http://ftp.iza.org/dp11421.pdf

Alwin, D.F., Braun, M., \& Scott. J. (1992). The Separation of Work and the Family: Attitudes towards Women's Labour-Force Participation in Germany, Great Britain, and the United States. European Sociological Review, 8(1),13-37.

Astin, A. W. (1964) Personal and environmental factors associated with college dropouts among high aptitude students. Journal of Educational Psychology, 55, 219-227. 
Astin, A. W. (1972). The Measured Effects of Higher Education. The ANNALS of the American Academy of Political and Social Science, 404(1), 1-20.

Astin, A. W. (1975). Preventing students from dropping out. San Francisco: Jossey-Bass.

Astin, A.W. (1977). Four critical years: Effects of college beliefs, attitudes and knowledge. San Francisco, USA. Jossey Bass Publishing.

Astin, A. W. (1985). Involvement: The cornerstone of excellence. Change, 17, 35-39.

Averett, S., \& Burton, M.L. (1996). College Attendance and the College Wage Premium: Differences by Gender. Economics of Education Review. 15(1), 37-49.

Ayalon, H. (2003) Women and Men Go to University: Mathematical Background and Gender Differences in Choice of Field in Higher Education. Sex Roles, 48, 277-290.

Bailey, M.J. (2006). More Power to the Pill: The Impact of Contraceptive Freedom on Women's Life Cycle and Labor Supply. Quarterly Journal of Economics. 121(1), 289-320.

Ball, R. \& Halwachi, J. (1987). Performance indicators in higher education. Higher Education, 16, 393-405.

Ball, R. \& Wilkinson, R. (1994) The use and abuse of performance indicators in UK higher education. Higher Education, 27, 417-427.

Bayer, A. E. (1968) The College Drop-out: Factors Affecting Senior College Completion. Sociology of Education, 41(3), 305-316.

Bean, J. P. (1980). Dropouts and turnover: The synthesis and test of a causal model of student attrition. Research in Higher Education, 12, 155-187.

Bean, J. P. (1983). The application of a model of turnover in work organizations to the student attrition process. The Review of Higher Education, 6(2), 129-148

Bean, J. P., \& Metzner, B. S. (1985). A Conceptual Model of Nontraditional Undergraduate Student Attrition. Review of Educational Research, 55(4), 485-540.

Becker, G. (1962) Investment in Human Capital: A Theoretical Analysis, Journal of Political Economy, 70(5), Part 2, 9-49.

Berger, J. B. \& Lyon, S. C. (2005). Past to present: A historical look at retention. In A. Seidman (Ed.), College student retention: Formula for student success, Westport, CT: Praeger Publishers.

Berger, J.B. \& Milem, J.F. (1999) The role of student involvement and perceptions of integration in a causal model of student persistence. Research in Higher Education, 40(6), 641-664.

Bragg, E. W. (1956) A study of student withdrawal at "W. U." Journal of Educational Psychology, 47, 199-202.

Braxton, J., \& Lien, L. (2000). The viability of academic integration as a central construct in Tinto's interactionalist theory of college student departure. In J. Braxton (Ed.), Reworking the Student Departure Puzzle (pp. 11-28). Nashville: Vanderbilt University Press.

Bradley, C. (1993) Sex Bias in Student Assessment Overlooked? Assessment \& Evaluation in Higher Education, 18(1), 3-8.

Breiman, J.H. Friedman, R.A. Olshen \& C.J. Stone, C.J. (1984). Classification and Regression Trees. Chapman and Hall, New York (1984)

Brint, S. (2001) Professionals and the knowledge economy: Rethinking the theory of post-industrial society. Current Sociology, 49(4), 101-132

Brown, P., A. Hesketh (2004). The Mismanagement of Talent. - Employability and Jobs in the Knowledge Economy, Oxford, Oxford University Press.

Buchmann, C. \& DiPrete, T. A. (2006). The Growing Female Advantage in College Completion: The Role of Family Background and Academic Achievement, American Sociological Review, 71(4), 515-41.

Buchmann, C., DiPrete, T. A. \& McDaniel, A. (2008) Gender Inequalities in Education. Annual Review of Sociology, 34,319-37.

Conger, D. \& Dickson, L. (2017) Gender Imbalance in Higher Education: Insights for College Administrators and Researchers. Research in Higher Education, 58(2), 214-230

Cope, R.G, Pailthorpand, K.G., Trap, D.C., Skaling, M., \& Hewit, R.G. (1971) An investigation of entrance characteristics related to types of college dropouts. Final Report, University of Washington, https://files.eric.ed.gov/fulltext/ED052749.pdf. 
Crippa F., Mazzoleni M. \& Zenga M. (2016). Departures from the formal of actual students' university careers: an application of non-homogeneous fuzzy Markov chains, Journal of Applied Statistics, 43(1), 16-30.

Darley, J. G. (1962) Promise and performance. Berkeley: Center for the Study of Higher Education, University of California.

De'ath, G. (2002). Multivariate Regression Trees: A New Technique for Modeling SpeciesEnvironment Relationships. Ecology, 83(4): 1105-1117, https://doi:10.2307/3071917

De'ath, G. (2004). mvpart: Multivariate partitioning. R package version 1.1-1, ftp://ftp.auckland.ac.nz/pub/software/CRAN/contrib/main/Descriptions/mvpart.html Accessed 25 May 2019

Demos, G. D. (1968), Analysis of College Dropouts-Some Manifest and Covert Reasons. The Personnel and Guidance Journal, 46,681-684. doi:10.1002/j.2164-4918.1968.tb03588.x

Diprete, T. A. \& Buchmann, C. (2006). Gender-specific trends in the value of education and the emerging gender gap in college completion. Demography, 43(I), 1-24

Dougherty, C. (2005). Why are the Returns to Schooling Higher for Women than for Men? Journal of Human Resources, 40(4), 969-988.

Draper D., \& Gittoes M. (2004). Statistical analysis of performance indicators in UK higher education. Journal of the Royal Statistical Society: Series A (Statistics in Society), 167, 449-474

Dryler, H. (1998). Parental Role Models, Gender and Educational Choice. British Journal of Sociology, 49(3), 375-398.

Edwards, L.N. \& Pasquale, M.P. (2003). Women's Higher Education in Japan: Family Background, Economic Factors and the Equal Employment Opportunity Law. Journal of the Japanese and International Economies, 17(1), 1-32.

Eckland, B. K. \& Henderson, L. B. (1981) College Attainment Four Years After High School. Report prepared for the National Center for Educational Statistics, Office of Educational Research and Improvement, U.S. Department of Education. Research Triangle Park, NC: Research Triangle Institute.

Embry, L.R. (1982) The relation of selected personal, environmental, and academic characteristics to student persistence in different types of institutions. $\mathrm{PhD}$ thesis The University of Arizona, http://hdl.handle.net/10150/185015

Evers, F., \& Mancuso, M. (2006). Where are the boys? Gender imbalance in higher education. Higher Education Management and Policy, 18(2), 1-13.

Fetters, W. (1977) Withdrawal from Institutions of Higher Education. National Center for Education Statistics, Washington, DC.

Gaither, G., Nedweck, B.P. \& Neal, J.E. (1994) Measuring up: The promises and pitfalls of performance indicators in higher education. ASHE-ERIC Higher Education Report Series. 23(5)

Gentry, R. (2014) Sustaining college students' persistence and achievement through exemplary instructional strategies. Research in Higher Education Journal.

Gammie, E., Paver, B., Gammie, B. \& Duncan, F. (2003) Gender differences in accounting education: an undergraduate exploration, Accounting Education, 12(2), 177-196.

Gilman, A. (1888) Women who go to college. The Century Magazine, 36, September, 714-718.

Goldin, C. (2004). The Long Road to the Fast Track: Career and Family. The ANNALS of the American Academy of Political and Social Science, 596(1), 20-35.

Goldin, C., \& Katz, L.F. (2002). The Power of the Pill: Oral Contraceptives and Women's Career and Marriage Decisions. Journal of Political Economy, 110(4), 730-770.

Goldin, C., Katz, L. \& Kuziemko, I. (2006). The Homecoming of American College Women: The Reversal of the College Gender Gap. Journal of Economic Perspectives, 20(4), 133-156.

Grebennikov, L., \& Skaines, I. (2009). Gender and higher education experience: A case study. Higher Education Research \& Development, 28(1), 71-84.

Häkkinen, I. S. \& Uusitalo, R. (2003). The Effect of a Student Aid Reform on Graduation: A Duration Analysis, Uppsala University, Department of Economics Working Paper, 8. 
Harper, P. R., Knight, V. A. \& Marshall, A. H. (2012) Discrete conditional phase-type models utilising classification trees: application to modelling health service capacities. European Journal of Operational Research, 219(3), 522-530.

Herzog, S. (2005). Measuring determinants of student return vs. dropout/ stopout transfer: a first-tosecond year analysis of new freshmen. Research in Higher Education, 46(8), 883-928.

Hilton, T. L. \& Schrader, W. B. (1987) Pathways to Graduate School: An Empirical Study Based on National Longitudinal Data. (Final report, GRE No. 82-21), Princeton, N.J.: Educational Testing Service.

Hippe, R. \& Perrin, F. (2017) Gender equality in human capital and fertility in the European regions in the past, Investigaciones de Historia Económica, 13(3), 166-179, https://doi.org/10.1016/j.ihe.2017.02.001.

Hoskins, S., Newstead, S. \& Dennis, I. (1997). Degree performance as a function of age, gender, prior qualifications and discipline studied. Assessment \& Evaluation in Higher Education, 22, 317-28

Hosmer D.W., Lameshow S. \& May S. (2008) Applied Survival Analysis, 2nd ed. Hoboken, NJ: John Wiley

Iffert, R. E. (1958) Retention and withdrawal of college students. (U.S. Department of Health, Education and Welfare, Bulletin No. 1). Washington, D. C.: U.S. Government Printing Office.

Ishitani, T.T. (2006) Studying Attrition and Degree Completion Behavior among First-Generation College Students in the United States. The Journal of Higher Education, 77(5), 861-885.

Jacobs J. A. (1996). Gender inequality and higher education. Annual Review of Sociology, 22,15385

Jacob, B. (2002). Where the Boys Aren't: Non-cognitive Skills, Returns to School and the Gender Gap in Higher Education. Economics of Education Review, 21, 589-598.

Johansson, C. B., \& Rossmann, J. E. (1973) Persistence at a liberal arts college: A replicated, fiveyear longitudinal study. Journal of Counseling Psychology, 20, 1-9.

Johnes, J. \& Taylor, J. (1989) Undergraduate non-completion rates: Differences between UK universities. Higher Education, 18(2), 209-225

Jorgensen, S., Ferraro, V., Fichten, C., \& Havel, A., (2009). Predicting college retention and dropout: Sex and disability. ERIC Online Submission ED505873.

Kalamatianou, A. G. \& McClean, S. (2003) The Perpetual Student: Modeling Duration of Undergraduate Studies Based on Lifetime-Type Educational Data, Lifetime Data Analysis, 9, 311-330.

Kaplan, E. L. \& Meier, P. (1958) Nonparametric estimation from incomplete observations. Journal or American Statistical Association, 53, 457-481

Kruskal, W., \& Wallis, W. (1952). Use of Ranks in One-Criterion Variance Analysis. Journal of the American Statistical Association,47(260), 583-621.

Lassibille, G. \& Navarro Gómez, M.L. (2011). How Long Does it Take to Earn a Higher Education Degree in Spain? Research in Higher Education, 52, 63-80.

Löfgren, C. \& Ohlsson, H. (1999). What Determines When Undergraduates Complete their Theses? Evidence from Two Economics Departments, Economics of Education Review, 18(1), 79-88.

Lombardo, R.\&Passarelli, G. (2011) Graduates' Job Quality after a Higher Education Reform: Evidence Regarding Second Level Graduates from a University in Southern Italy, Research in Applied Economics, 3(2), https://doi.org/10.5296/rae.v3i2.1074

Malik, S., \& Courtney, K. (2011). Higher education and women's empowerment in Pakistan. Gender and Education, 23 (1), 29-45. http://dx.doi.org/10.1080/09540251003674071

Mantel, Nathan (1966). Evaluation of survival data and two new rank order statistics arising in its consideration. Cancer Chemotherapy Reports, 50(3), 163-70

Mantel N. \& Haenszel W. (1959) Statistical aspects of the analysis of data from retrospective studies. Journal of the National Cancer Institute, 22,719-748.

Márquez-Vera, C., Cano, A., Romero, C., Noaman, A. Y. M., Mousa Fardoun, H., \& Ventura, S. (2016). Early dropout prediction using data mining: A case study with high school students. Expert Systems, 33(1), 107-124. 
McGuinness, S. \& Byrne, D. (2014): Examining the Relationships between Labour Market Mismatches, Earnings and Job Satisfaction among Immigrant Graduates in Europe. IZA Working Paper No. 8440.

McNabb, R., Sarmistha, P. \& Sloane, P. J. (2002) Gender Differences in Educational Attainment: The Case of University Students in England and Wales. Economica, 69, 481-503.

McNeely, J. H. (1937). College student mortality. U.S. Office of Education, Bulletin 1937, no. 11. Washington, D.C.: U.S. Government Printing Office.

Mellanby, A. R., Rees, J. B.\& Tripp, J. H. (2000) Peer-led and adult-led school health education: a critical review of available comparative research, Health Education Research, 15(5), 533-545.

Mendick, H.(2005) A Beautiful Myth? The Gendering of Being/Doing "Good at Maths". Gender and Education, 17 (2), 203-219.

Morley, L., Lugg, R. (2009) Mapping Meritocracy: Intersecting Gender, Poverty and Higher Educational Opportunity Structures, Higher Education Policy, 22, 37-60

Mullen, A. L., \& Baker, J. (2018). Gender Gaps in Undergraduate Fields of Study: Do College Characteristics Matter? Socius, 4, 1-14.

Murphy, K.M. \& Welch, F. (1992) The Structure of Wages. Quarterly Journal of Economics, 107, 215-236.

Nelson, A. G. (1966). College Characteristics Associated with Freshman Attrition. The Personnel and Guidance Journal, 44,1046-1050. doi:10.1002/j.2164-4918.1966.tb03831.x

Ono, H. (2004). Are Sons and Daughters Substitutable? Allocation of Family Resources in Contemporary Japan. Journal of the Japanese and International Economics. 18, 143-160.

OECD (2008) Higher Education to 2030. Demography. 1. Paris, OECD.

OECD (2012) Gender Equality in Education, Employment and Entrepreneurship: Final Report to the MCM 2012, https://www.oecd.org/employment/50423364.pdf. Accessed 25 May 2019.

O’Dea, R.E., Lagisz, M., Jennions, M.D. \& Nakagawa, S. (2018) Gender differences in individual variation in academic grades fail to fit expected patterns for STEM. Nature Communication, 9 , number 3777

Panos R.J. \& Astin A.W. (1968). Attrition among college students. American Educational Research Journal, 5, 57-72.

Pantages, T. J. \& Creedon, C. F. (1978). Studies of College Attrition: 1950-1975. Review of Educational Research, 48(1), 49-101.

Perchinunno, P., Bilancia, M. \& Vitale, D. (2019). A Statistical Analysis of Factors Affecting Higher Education Dropouts. Social Indicators Research, doi: 10.1007/s11205-019-02249-y.

R Development Core Team, R. F. F. S. C. (2018). R: A language and environment for statistical computing.

Rovai, A. R. (2003). In search of higher persistence rates in distance education online programs. The Internet and Higher Education, 6(1), 1-16.

Rudd, E. (1984). A comparison between the results achieved by women and men studying for first degrees in British universities. Studies in Higher Education, 9, 47

Sax, L.J., Kanny, M.A., Riggers-Piehl, T.A., Whang, H., Paulson, L.N. (2015) “But I'm Not Good at Math": The Changing Salience of Mathematical Self-Concept in Shaping Women's and Men's STEM Aspirations. Research in Higher Education, 56, 813-842

Schapiro, M. \& O'Malley, M. (1991) Progression to graduate school from the elite universities. Economics of Education Review, 10, 227-244

Schwarz, G. E. (1978). Estimating the dimension of a model, Annals of Statistics, 6(2), 461-464

Scott, J. (2006) Family and Gender Roles: How Attitudes Are Changing. GeNet Working Paper No. 21.

Scurry, T. \& Blenkinsopp, J. (2011), Under-employment among recent graduates: a review of the literature. Personnel Review, 40(5), 643-659

Severiens, S., \& ten Dam, G. (2012). Leaving college: A gender comparison in male and femaledominated programs. Research in Higher Education, 53(4), 453-470.

Sewell, W., \& Shah, V. (1967). Socioeconomic status, intelligence, and the attainment of higher education. Sociology of Education, 40(1), 1-23. 
Slocum, W. L. (1956) Social factors involved in academic mortality. College and University, 32, 53-64.

Somers, P.A. (1995). Evaluating institutional student aid policies. New Directions for Higher Education, 1995: 65-74.

Sommers, C. H. (2001). The war against boys: How misguided feminism is harming our young men. New York: Simon and Schuser.

Spady W. (1971). Dropouts from Higher Education: Toward an Empirical Model. Interchange, 2(3), 38-62.

Stinebrickner T. \& Stinebrickner, R. (2012) Learning about Academic Ability and the College Dropout Decision. Journal of Labor Economics, 30(4), 707 - 748

Suddarth, B. M. (1957). Factors influencing the graduation of freshmen who enrol at Purdue University. Unpublished report. Cited in N. Sanford (Ed.), The American college. New York: Wiley, 1962.

Summerskill, J., \& Darling, C. D. (1955). Sex differences in adjustment to college. Journal of Educational Psychology, 46(6), 355-361.

Tansel, A. (2002). Determinants of School Attainment of Boys and Girls in Turkey: Individual, Household and Community Factors. Economics of Education Review, 21, 455-470.

Therneau, T.M., Atkinson, B. (2019). Package 'rpart'. $R$ package version 4.1-15, https://cran.rproject.org/web/packages/rpart/rpart.pdf. Accessed 25 May 2019

Therneau, T.M., Lumley, T. (2019). survival: Survival Analysis. R package version 2.44-1.1, https://cran.r-project.org/web/packages/survival/index.html. Accessed 25 May 2019

Tinto, V. (1975) Dropout from Higher Education: A Theoretical Synthesis of Recent Research. Review of Educational Research, 45(1), 89-125.

Tinto, V. (1993). Leaving College: Rethinking the Causes and Cures of Student Attrition. Chicago: The University of Chicago Press.

Tinto, V. (2012). Completing College: Rethinking Institutional Action. Chicago: The University of Chicago Press.

Titus, M. (2006). Understanding college degree completion of students with low socioeconomic status: The influence of the Institutional Financial Context. Research in Higher Education, 47(4), 371-398

Trent, J., \& Ruyle, J. (1965). Variations, flow and patterns of college attendance. College and University, 41, 61-76.

Trueman, M., \& Hartley, J. (1996). A comparison between the time-management skills and academic performance of mature and traditional-entry students. Higher Education, 32, 199-215.

UNESCO (2009). Trends in Global Higher Education: Tracking an Academic Revolution. http://www.cep.edu.rs/public/Altbach, Reisberg, Rumbley Tracking an Academic Revolution 2_UNESCO 2009.pdf. Accessed 26 July 2016.

UNESCO (2017). Accountability in education: meeting our commitments; Global education monitoring report. https://unesdoc.unesco.org/ark:/48223/pf0000259338. Accessed 26 July 2016

Vincent-Lancrin, S. (2008). The reversal of gender inequalities in higher education: An on-going trend. Higher Education to 2030. Demography, 1, 265-298

Webster, A.L. \& Shower, V.E. (2010) Measuring Predictors of Student Retention Rates. American Journal of Economics and Business Administration, 3(2), 296-306.

Wei L.J. (1992). The accelerated failure time model: a useful alternative to the Cox regression model in survival analysis. Statistics in Medicine, 11, 1871-1879

Wolffensberger, J. (1993) Science is truly a male world. The interconnectedness of knowledge, gender and power within university education. Gender and Education, 5(1), 37-54.

Woodfield, R., Jessop, D., \& McMillan, L. (2006). Gender differences in undergraduate attendance rates. Studies in Higher Education, 31, 1-22.

Yorke, M. (1999) Assuring quality and standards in globalised higher education. Quality Assurance in Education, 7(1), 14-24. 
Yonezawa, A. \& Kim, T. (2008) The Future of Higher Education in a Context of a Shrinking Student Population: Policy Challenges for Japan and Korea, in S. Vincent-Lancrin (ed.), Higher Education 2030. Volume 1: Demography, OECD Publishing, Paris. 